\title{
Does extrusion occur at both tips of the Taiwan collision belt? Insights from active deformation studies in the Ilan Plain and Pingtung Plain regions
}

\author{
Jacques Angelier ${ }^{\mathrm{a}, \mathrm{b}, *}$, Tsui-Yü Chang ${ }^{\mathrm{c}, \mathrm{d}}$, Jyr-Ching Hu ${ }^{\mathrm{e}}$, Chung-Pai Chang ${ }^{\mathrm{f}}$, Lionel Siame ${ }^{\mathrm{g}}$, \\ Jian-Cheng Lee ${ }^{h}$, Benoît Deffontaines ${ }^{i}$, Hao-Tsu Chu ${ }^{j}$, Chia-Yü Lu ${ }^{\mathrm{e}}$ \\ a Observatoire Océanologique de Villefranche, Géosciences Azur, B.P. 48, 06235, France \\ ${ }^{\mathrm{b}}$ Institut Universitaire de France France \\ ${ }^{\mathrm{c}}$ Institute of Applied Geosciences, National Taiwan Ocean University, Keelung, Taiwan, ROC \\ ${ }^{\mathrm{d}}$ Institute of Oceanography, National Taiwan University, Taipei, Taiwan, ROC \\ e Department of Earth Sciences, National Taiwan University, Taipei, Taiwan, ROC \\ ${ }^{\mathrm{f}}$ National Central University, Chungli, Taiwan, ROC \\ ${ }^{g}$ Cérège, Université Aix-Marseille, France \\ ${ }^{\mathrm{h}}$ Institute of Earth Sciences, Academia Sinica, Nankang, Taipei, Taiwan, ROC \\ ${ }^{i}$ Géomatériaux et Géologie de l'Ingénieur, Université de Marne-la-Vallée, France \\ ${ }^{\mathrm{j}}$ Central Geological Survey, Taipei, R.O.C., Taiwan
}

Available online 3 December 2007

\begin{abstract}
We analyse the present-day deformation in two key areas of the Taiwan collision belt, the Ilan Plain to the NW and the Pingtung Plain to the SW. Our approach is mainly based on consideration of horizontal displacement revealed by recent geodetic (GPS) surveys, derived strain rate tensors indicating horizontal deformation and three-dimensional seismotectonic stress regimes issued from inversion of focal mechanisms of earthquakes. We reconstruct a consistent, albeit complex, tectonic pattern involving non-rigid rotations (clockwise in NE Taiwan, anticlockwise in SW Taiwan), transitions from pure compression near the mountains to transtension near the sea and simple shear affecting the deforming domain (NW-SE left-lateral in NE Taiwan, NNE-SSW right-lateral in SW Taiwan). These tectonic patterns reflect lateral extrusion processes towards mechanically weak domains with respect to collision zone, i.e., adjacent subduction zones (Ryukyu to the NE, Manila to the SW). The extrusion of the Ilan Plain area occurs towards the SE, whereas that of the Pingtung Plain area occurs towards the SW. The extrusion in NE Taiwan is facilitated by the opening of the Okinawa Trough, so that velocity and deformation rates are higher than in SW Taiwan despite less active collision in this northern area. The symmetry of the extrusion patterns is altered by differences in relative positions and orientations of collision belt and adjacent subduction zones, which depend on the plate tectonic configuration and tectonic history of the Taiwan region.
\end{abstract}

(C) 2007 Elsevier B.V. All rights reserved.

Keywords: Collision; Extrusion; Earthquakes; Extension; Seismogenic stress; Taiwan

\section{Introduction}

Neotectonic studies allow better understanding of the active deformation processes, based on field analysis of active faults, geodetic surveys, remote sensing and seismology. Other

\footnotetext{
* Corresponding author. University P. \& M. Curie, Observatoire de Villefranche, UPMC - Geosciences Azur, La Darse, BP 48, 06235 Villefranche-sur-Mer, France.

E-mail address: jacques.angelier@geoazur.obs-vlfr.fr (J. Angelier).
}

approaches, such as structural geology and morphological analysis, allow evaluation of the relationships between presentday and long-term deformation, being aware that the seismotectonic variations within the seismic cycle may introduce major bias in the evaluation of active deformation. We are combining these different approaches to investigate the geometrical and mechanical relationships between the Taiwan collision belt and the adjacent subduction zones. In this paper, particular attention is paid to the present-day patterns of active deformation and seismotectonic stress at the NE and SW tips of this NNW-SSE trending, approximately $400 \mathrm{~km}$ long mountain belt (Fig. 1). 


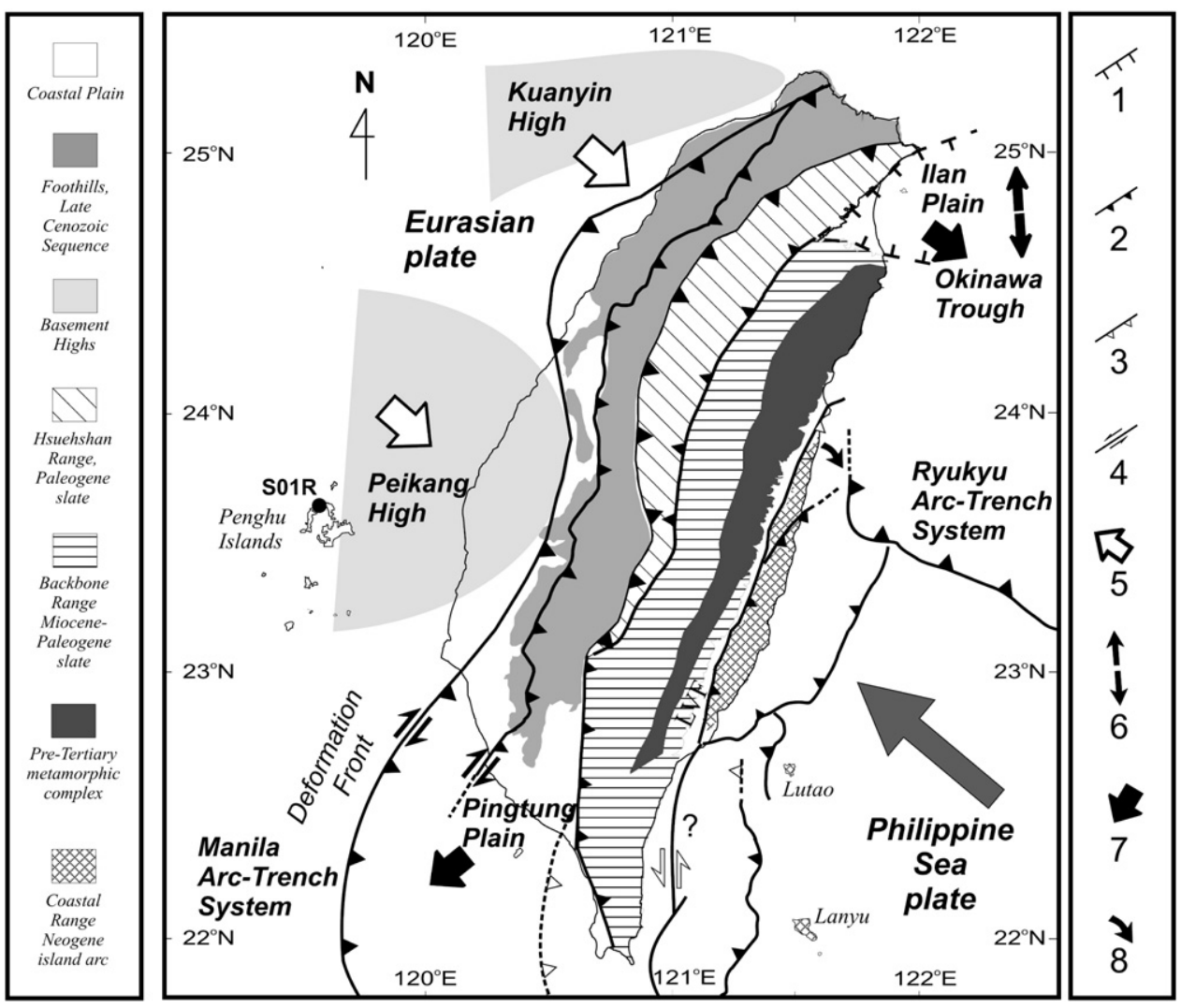

Fig. 1. Tectonic framework and main structural units of the Taiwan collision zone (adapted from Ho 1975, 1986; Teng, 1990; Hu et al., 2001; Lacombe et al., 2001; Malavieille et al., 2002, and geological maps). Large dark grey arrow, direction of plate convergence of Philippine Sea plate relative to Eurasia (South China). Major thrust faults with triangles on upthrust side. Caption on left: main stratigraphic-tectonic zones. Caption on right: 1 normal fault; 2 active thrust fault; 3 inactive thrust fault; 4 strike-slip fault; 5 arrow indicating the indenting effect of rigid promontory (basement high) on the active belt front; 6 back-arc opening; 7 black arrow indicating extrusion and tectonic escape (Ilan Plain and Pingtung Plain areas, this paper); 8, migration of thrust front. LVF, Longitudinal Valley Fault. Black dot: permanent station S01R (Penghu Islands, Taiwan Strait) of the Taiwan GPS network (Yu et al., 1997), taken as a reference in geodetic analysis.

The concept of lateral extrusion along a collision zone has been proposed in papers concerning Tibet and Himalaya (Molnar and Tapponnier, 1978; Tapponnier et al., 1983) and later extended to other mountain belts such as the Alps (Ratschbacher and Merle, 1991). In simple words, tectonic extrusion describes the lateral motion of structural units that move toward a weaker domain with respect to the mountain belt, in response to collision-induced shortening. The weak domain is often represented by a free boundary in analogue or numerical models. Such a mechanical exaggeration aims at producing clearer results. In real situations, the velocity and amplitude of extrusion are functions of both the shortening across the mountain belt and the contrast in mechanical strength between the structural units within the belt and the adjacent weaker domains. We aim at showing that despite the small size of the Taiwan mountain belt (as compared with Himalaya or Alps), significant extrusion occurs at both tips of the Taiwan collision zone, in two key areas close to the adjacent arc-andtrench systems where subductions occur.

The crucial areas are the Pingtung Plain of SW Taiwan and the Ilan Plain of NE Taiwan (Fig. 1). The Pingtung Plain is located in the transition domain between the Taiwan collision zone (to the North) and the subduction zones of the Manila Trench and Luzon Arc (to the South). The Ilan Plain is located at the western tip of the Okinawa Trough, the back-arc basin of the Ryukyu subduction zone. With respect to other segments of the mountain belt between $23^{\circ} \mathrm{N}$ and $24.5^{\circ} \mathrm{N}$, both these areas show significant deviations of horizontal displacement vectors revealed by the GPS studies. In addition to these deviations, significant changes affect the trends of the smallest and largest horizontal stresses revealed by inversion of subsets of focal mechanisms of earthquakes. In this paper, we analyse and interpret the patterns of displacement vectors and related principal axes of deformation (in the horizontal plane), as well as the patterns of seismotectonic stress revealed by earthquakes (in three dimensions). These local displacement, strain and stress fields, which markedly differ from those usually reconstructed within the collision belt, are strongly influenced by extrusion and lateral escape at both tips of the Taiwan collision zone.

\section{General structure}

The Taiwan mountain belt results from oblique collision between the Luzon volcanic arc of the Philippine Sea Plate and the South China continental margin of Eurasia (Suppe, 1984), which explains its structure (Ho, 1986) and seismic activity (Tsai, 1986). The still ongoing collision between the Luzon Arc 
and South China started about 5 Ma ago (Chai, 1972; Suppe, 1984; Angelier, 1986; Ho, 1986; Angelier, 1990a; Teng, 1990). A general agreement has been reached concerning the plate tectonic framework in and around Taiwan, despite some differences in kinematic reconstructions (e.g., Angelier, 1990a; Teng, 1990). The Taiwan collision belt (Fig. 1) connects the Ryukyu subduction zone (Philippine Sea Plate subducting northwards beneath Eurasian plate), and the Manila subduction zone (South China Sea of Eurasia subducting eastwards beneath Philippine Sea Plate).

The typical tectonic regime across the Taiwan belt is dominated by NW-SE trending compression, as revealed by stress inversions of Pliocene-Quaternary fault slip data sets (Angelier et al., 1986; Barrier and Angelier, 1986; Angelier et al., 1990) and present-day focal mechanisms of earthquakes (Yeh et al., 1991; Kao and Angelier, 2001; Angelier, 2002). Geodetic analyses also revealed dominating NW-SE contraction (Yu and Chen, 1994; Yu et al., 1997, 1999; Yu and Kuo, 2001; Chang et al., 2003).

Mapping synthesis of active stress patterns and numerical modelling at the scale of the Taiwan Island showed that this pattern of stress and displacement is consistent with the boundary conditions that result from plate motion and configuration, and also with reasonable rheological properties of major regional units involved in the subduction and collision processes in and around Taiwan (Lee and Angelier, 1994; Hu et al., 1996, 2001). This geodynamic context is not presented again in this paper, but should be kept in mind while analysing the patterns of displacement (Section 3), strain (Section 4) and stress (Section 5) that prevail in the belt tip domains of the Pingtung Plain and Ilan Plain regions. Likewise, the geological structure and geophysical properties of these two domains are not discussed in detail hereafter. Especially, the detailed analysis of the relationships between short-term and long-term tectonism is left for a forthcoming paper. We rather focus on some active tectonic features that highlight the originality of the Pingtung Plain and Ilan Plain regions with respect to other regions of the Taiwan collision zone (Fig. 1). Both these areas are characterised by flat topography close to sea level and local subsidence.

The Ilan Plain is surrounded by the high mountains of the Hsuehshan Range to the Northwest and the Central Range to the South. This deltaic plain is fed by the Lanyang Chi drainage network, which discharges annually roughly 10 million tons of sediment (Liu et al., 2006) into the southwestern submarine head of the Okinawa Trough. The Ilan Plain exhibits a triangular shape (Fig. 2a) and its eastern coast faces the western tip of the Okinawa Trough (Fig. 1).

The Pingtung Plain is bounded by the high mountains of the Central Range to the East and the Southwestern Foothills to the West. This deltaic plain is fed by the Kaoping Chi drainage network, which discharges annually roughly 15 million tons of sediment ( $\mathrm{Li}$ et al., 2005) into the submarine Manila accretionary prism area incised by the Penghu canyon southwest off Kaohsiung. It is elongated $\mathrm{N}-\mathrm{S}$ (Fig. 2b) and its southern coastal area is the onland extension of the accretionary prism of the Manila subduction zone (Fig. 1).
From the tectonic point of view, the triangular shape of the Ilan basin (Fig. 3a) reflects the westward, onshore propagation of the Okinawa back-arc trough. In connection with this extensional domain, the Ilan Plain is bounded by normal faults to the south and northwest, where triangular facets can be depicted from the morphology (Lee et al., 1998b; Shyu et al., 2005). As a consequence, and also because of its normal faulting seismic activity, the Ilan Plain has been interpreted as an onland extension of the Okinawa Trough (Ho, 1986; Tsai, 1986), which is the back-arc basin of the Ryukyu Arc (Fig. 1). Because of active subsidence and high-rate sedimentation, the surface expression of the normal faults in the Ilan Plain is subdued. Even the fault scarps along the mountain are buried by Pleistocene-Holocene sediments.

To the southwest, upstream from the Ilan Plain, the deeply incised Lanyang Valley follows the Lishan Fault. As Fig. 3a shows, this major fault separates the Miocene Lishan Formation of the Central Range and the Eocene-Oligocene formations of the Hsuehshan Range (Ho, 1986). The complex evolution of this major fault zone could be deciphered by paleostress studies (Lee et al., 1997). The Lishan fault zone was inherited from a normal fault of the continental margin, subsequently reactivated as a major thrust and strike-slip fault, and finally became a backthrust bounding the pop-up structure of the Hsuehshan Range.

West of the Ilan Plain, near $24.7^{\circ} \mathrm{N}$ in latitude, the structural grain of both the folded Hsuehshan Range and the Western Foothills gradually changes in trend from South, where it is approximately oriented $\mathrm{N} 25^{\circ} \mathrm{E}$, to North, where it becomes $\mathrm{N} 65^{\circ} \mathrm{E}$ (Figs. 2a and 3a). This major change partly results from a clockwise rotation of $20-30^{\circ}$ that affected the northern segment of the Taiwan belt, as revealed by paleomagnetic studies (Lee et al., 1991, 1998a). The original belt curvature accounts for the remaining bend, about $10-20^{\circ}$. Because of the rotation, the structural evolution of the northernmost segment of the Taiwan belt, in the Taipei-Keelung region, involves specific local extension and along-fold strike-slip ( $\mathrm{Lu}$ et al., 1995, 2001). The structure and deformation of the northern, WSW-ENE trending belt segment differ from those of the main, NNW-SSE trending mountain belt of central Taiwan.

The Pingtung Plain area of southwestern Taiwan is located in the transition zone between collision and subduction (Fig. 1). Despite its complexity, this region is characterised by relative structural continuity and homogeneous $\mathrm{N}-\mathrm{S}$ trend, from the Taiwan collision mountain belt to the North to the Hengchun Ridge-Manila Trench system to the South (Chang et al., 2002, 2009). The coastal area between Tainan and Kaohsiung is the southern part of the Plio-Pleistocene foreland basin that undergoes lithospheric flexuring attributed to the tectonic loading of the Central Range (Lin and Watts, 2002). Above this foreland domain to the East, the Western Foothills of Taiwan are composed of series of imbricated folds and thrust sheets affected by basementinvolved tectonics (Mouthereau et al., 2002).

Between the folded Pliocene and Pleistocene sediments of the southernmost Western Foothills to the West and the Miocene argillites, slates and meta-sandstones of the Central Range to the East (Fig. 3b), the Pingtung Plain is filled by unconsolidated coastal and estuarine sediments of the late Pleistocene and the 

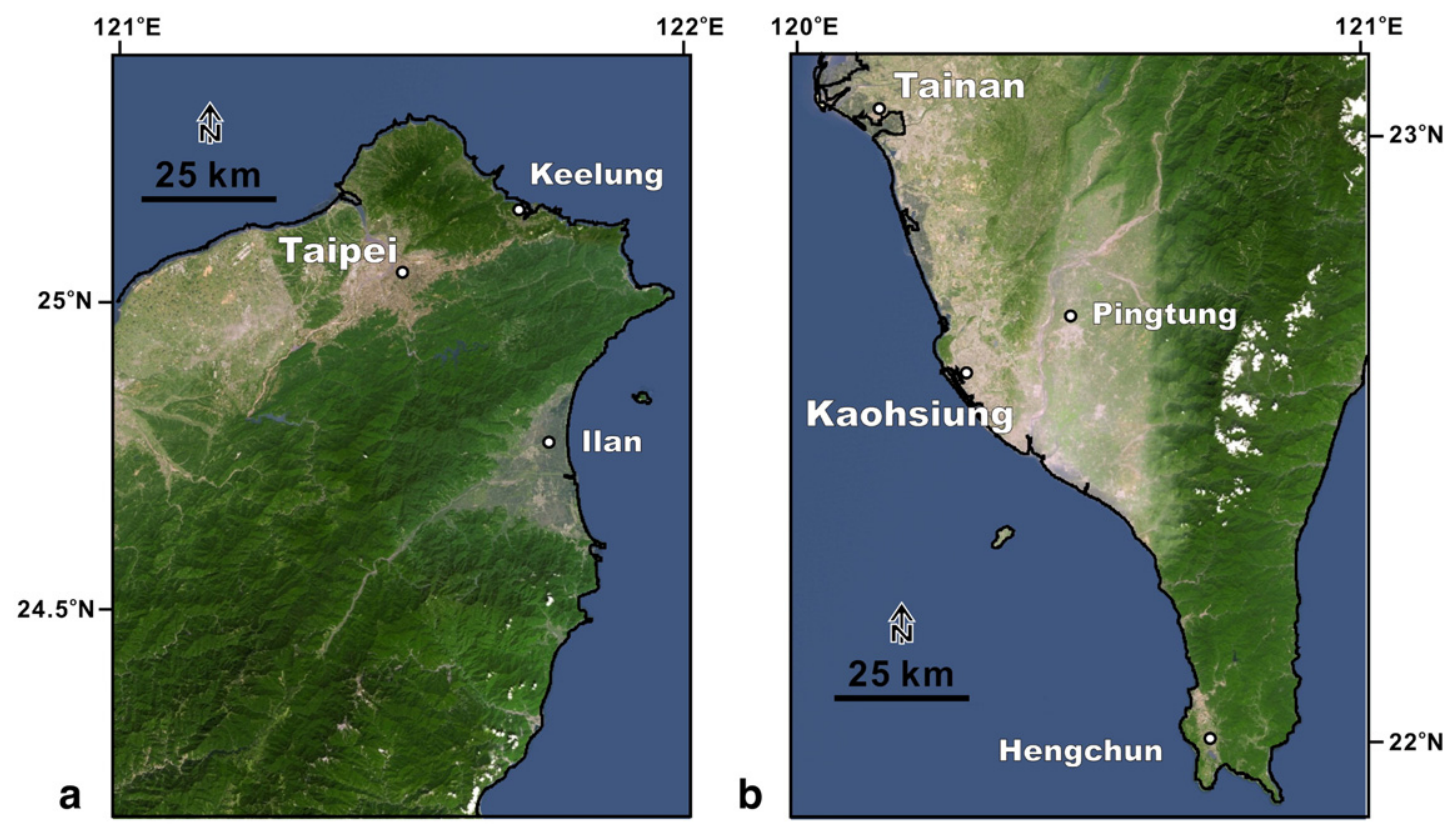

Fig. 2. Morphology of the Ilan Plain area (a) and the Pingtung Plain area (b). Shaded pictures from satellite imagery. Mountainous areas in white, plains in light grey. Note the presence of major river valleys as clear lines between darker mountainous domains (Layang Hsi for Ilan, Kaoping Hsi for Pingtung Plain).

Holocene. To the west, the Pingtung basin is bounded by the N $10^{\circ} \mathrm{E}$ trending escarpment of the buried Kaoping Fault. To the East, it is bounded by a major N-S trending fault, the Chaochou
Fault. In satellite images, the corresponding escarpment is one of the most visible features of Taiwan and appears as a welldefined straight line between the Pingtung Plain and the high
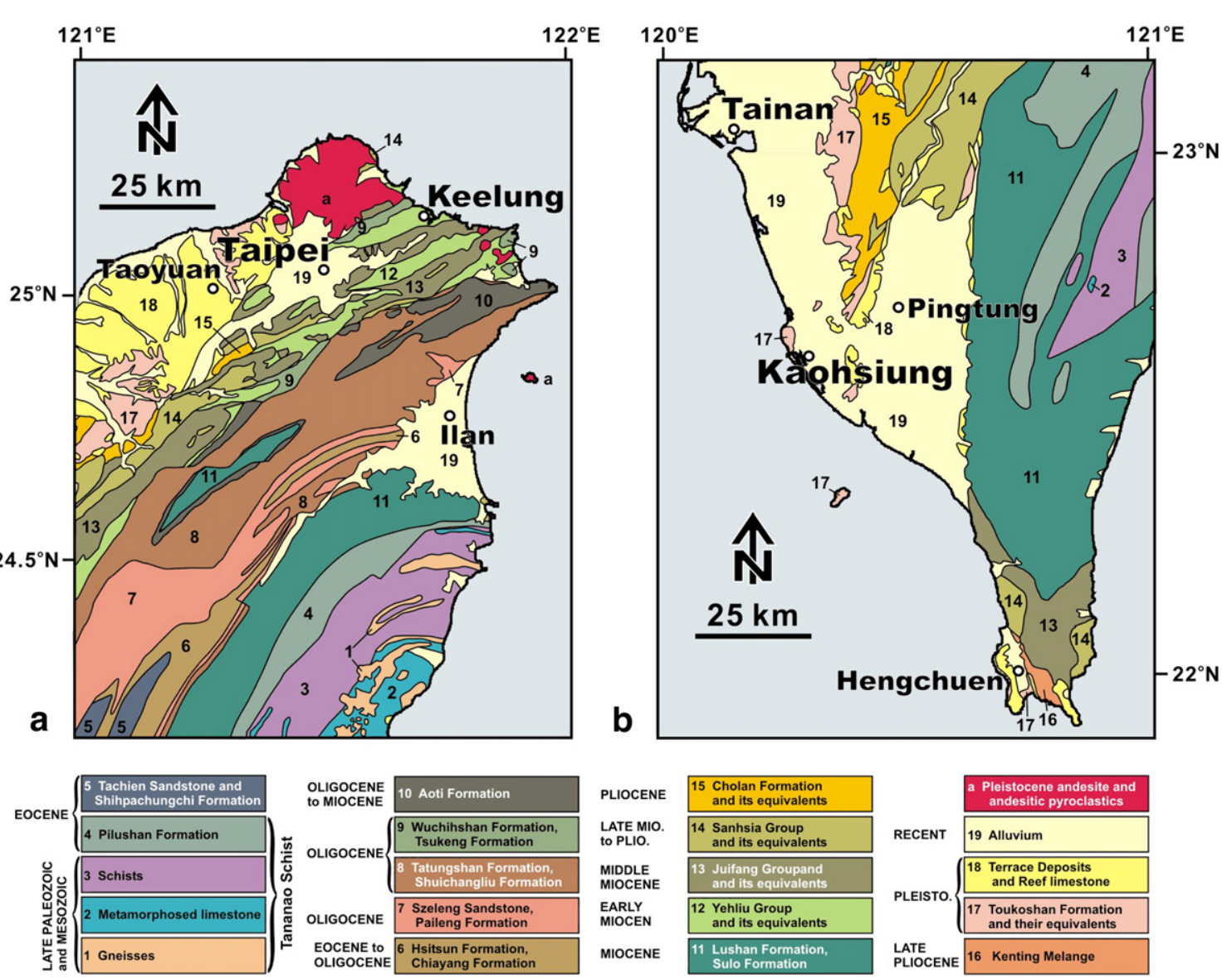

Fig. 3. Generalised geology of the Ilan Plain area (a) and the Pingtung Plain area (b). Adapted from the Geological Map of Taiwan and other maps. Note the presence of alluvium (19) and recent Quaternary deposits (18) at the surface in the Ilan and Pingtung Plains. 
mountains of the Central Range (Fig. 2b). To the south, the initial shortening of the forearc domain resulted in numerous offshore folds and thrust faults (Liu et al., 1997; Lundberg et al., 1997).

Recent studies have shown that southwestern Taiwan experienced transtensional tectonic movements that were interpreted in terms of tectonic escape (Lacombe et al., 1999). Along the Chaochou Fault, tectonic analyses of faults revealed a predominant transtensional tectonic regime with NNE-SSW to NE-SW extension and ESE-WNW to SE-NW compression (Chan et al., 2000). The change from transpression (to the North) to transtension (to the South) is a probable expression of both the transition from collision to subduction and the active extrusion of the study area towards the southeast.

\section{Present-day kinematics from GPS studies}

In this Section we interpret the horizontal velocity patterns revealed by recent GPS studies in the Pingtung Plain and Ilan Plain areas. Our purpose is not to describe again the geodetic networks and results that have been extensively presented by their authors. For a general presentation of the GPS in Taiwan the reader is referred to the pioneering work by $\mathrm{Yu}$ and Chen (1994) and Yu et al. (1997), who installed the 'Taiwan GPS Network' and interpreted the first results at the scale of the Taiwan island and surrounding islets. This network was later extended to the entire Taiwan-Luzon region (Yu et al., 1999) and particular analyses focused on areas such as the Longitudinal Valley of eastern Taiwan, the major suture between the Philippine Sea Plate and Eurasia (Yu and Kuo, 2001).

Although conventional geodesy had already revealed displacement in several active zones of Taiwan, the installation of the Taiwan GPS network as well as other satellite positioning networks represented a major advance in the studies of active deformation in Taiwan. However, the relatively low spatial density of GPS stations in several areas of Taiwan, including the Pingtung and Ilan regions, did not allow us to reconstruct the ongoing deformation in detail. Although we checked the overall consistency between our results and the general displacement pattern revealed by the Taiwan GPS Network, our analysis was thus primarily based on the horizontal displacement data issued from local, denser networks.

A complete analysis of deformation should take into account the vertical components of displacement. However, these displacements are affected by very large uncertainties, especially for the first 12 years of GPS data, which still precludes such an analysis. Fortunately, a simple geometrical evaluation with known values for both the horizontal and the vertical deformation shows that the impact of vertical displacement on horizontal displacements values is minor, generally smaller than uncertainties. As a consequence, our analysis concentrated on the horizontal components of displacement and deformation (Sections 3 and 4 of this paper, respectively). Because of this restriction, the geodetic data taken alone do not allow distinction between tectonic deformation regimes in three dimensions (for instance, a strike-slip regime cannot be identified because the value of the vertical strain with respect to horizontal ones is unknown). The analysis of focal mechanisms of earthquakes allowed us to determine the nature of seismotectonic regimes in three dimensions (Section 5 of this paper).

Most GPS horizontal velocity maps used in our work have been drawn with respect to a single station (S01R, located in Fig. 1) in the Paisha Island of the Penghu Archipelago, Taiwan Strait. It was also assumed that the azimuth from Paisha to Taipei, about $\mathrm{N} 52^{\circ} \mathrm{E}$, is constant. This choice did not affect the accuracy of relative displacement determinations, because these displacements were reconstructed from baseline length variations inside local GPS networks. The velocity fields displayed in the present Section are dependent on this kinematic reference, already used in previous GPS studies at the scale of Taiwan (Yu et al., 1997). These studies showed that the displacement of northwestern Taiwan (Taipei) is very small with respect to the Penghu Islands. The Penghu themselves are almost fixed with respect to South China (especially the Fukien Province). Thus, the reference chosen is appropriate to describe the displacements with respect to South China, which is the foreland of the Taiwan mountain belt.

According to the MOI (Ministry of Interior) GPS network of permanent GPS stations (data from 2003 to 2005, personal information from C.-C. Liu), the displacement of the sites that belong to the foreland of the Taiwan belt is quite homogeneous, about $32 \mathrm{~mm} / \mathrm{yr}$ towards the ESE in the ITRF2000 frame. This is the case for the stations in the Kinmen and Matsu Islands on the western side of the Taiwan Strait, as well as Hsinchu and Tachia stations (and two stations near Chiayi) on the eastern coast of the strait. Even the station of the Tungsha (Pratas) Island in the South China Sea displays similar displacement, about $35 \mathrm{~mm} / \mathrm{yr}$ towards the ESE in the same global frame. All these stations surround the station S01R of Paisha Island at distances between $50 \mathrm{~km}$ and $400 \mathrm{~km}$. This velocity distribution indicates that the horizontal deformation within the Taiwan Strait area, the foreland of the Taiwan belt, is negligible. According to the same sources, two northernmost stations of Taiwan (north of $\mathrm{N} 25^{\circ} \mathrm{N}$ ), which display a displacement of about $35 \mathrm{~mm} / \mathrm{yr}$ towards the ESE in the ITRF2000 frame, undergo significant displacement of about 2$3 \mathrm{~mm} / \mathrm{yr}$ towards the East relative to S01R (Paisha).

It would be possible to change the reference, which would affect the patterns of displacement vectors. Our results could have been displayed in a global frame, such as ITRF2000. However, in terms of tectonic analysis, such a change was not desirable: because South China moves with respect to Eurasia, the displacements would not have been illustrated with respect to the foreland of Taiwan. Because the Penghu area is stable with respect to South China and the Paisha-Taipei axis shows negligible rotation, the reference frame adopted (S01R Station and Paisha-Taipei direction fixed) is appropriate from the geodynamic point of view. This choice means that the velocity vectors describe the displacement of the stations of the studied two regions (Pingtung and Ilan plain areas) with respect to the foreland of the Taiwan collision zone, that is, the South China continental shelf, which geologically makes sense.

\subsection{The Pingtung Plain area}

A dense 'Pingtung GPS Network' was established in 1995 by the Central Geological Survey, Ministry of Economic 
Affairs, near Kaohsiung and Pingtung. Not only did this network allow monitoring the crustal deformation along and around major crustal fault zones, it also brought considerable help to analyses of the present-day land subsidence in the Pingtung area. This subsidence is induced by both the seaward extensional deformation and the overpumping in the southern Pingtung Plain. The Pingtung GPS Network was composed of 48 annually surveyed stations and one permanent station. The baselines range from 3 to $21 \mathrm{~km}$ in length, most of them being shorter than $10 \mathrm{~km}$. From August 1995 to August 1999, the mobile stations of the Pingtung GPS Network were surveyed 3-4 times with dual frequency geodetic GPS receivers. The technical conditions of these surveys and subsequent data processing (Shen et al., 2003), as well as the inferences for regional deformation (Hu et al., 2007) including subsidence (Hou et al., 2005; $\mathrm{Hu}$ et al., 2006) and fault behaviour, have already been described and are not discussed hereafter. Our kinematic analysis mainly relies on the pattern of horizontal displacements summarised in the simplified map of Fig. 4.

The uncertainty ellipses remained very small with respect to the horizontal displacement velocities (usually about one tenth of velocity vector length). This observation is important in terms of the velocity trends that we are interested in, because it shows that these trends cannot be affected by changes larger than few degrees. For the sake of clarity, these ellipses have been omitted in the map of Fig. 4. For a complete representation of velocities, including uncertainties, the reader is referred to the papers by Hou et al. (2005) and $\mathrm{Hu}$ et al. (2007).

The simplified map of velocities reveals surprisingly high levels of regularity in distribution of trends and values (Fig. 4). Most velocities are larger than $1 \mathrm{~cm} / \mathrm{yr}$ for the period considered. All displacement vectors are approximately westwarddirected. The most interesting aspect of this pattern is the good fit between the velocity vector trends and series of small circles (in grey in Fig. 4) with a common centre approximately located near $21.7^{\circ} \mathrm{N}-120.6^{\circ} \mathrm{E}$. This distribution clearly indicates anticlockwise rotation. This rotation, however, is certainly not a rigid rotation. Not only do the velocities vary little as a function of radius in the entire Pingtung Plain, they even slightly increase towards the south. Had the rotation been rigid, implying a constant angular velocity, the linear velocities would decrease from North to South, being proportional to circle radii. This is not the case. Thus, the small circles of Fig. 4 simply reveal the approximate path of particles in the deforming Pingtung Plain area.

Note that the choice of a reference frame affects the GPS displacement vectors, which subsequently affects the bestfitting set of circle. Had a different reference been adopted, the pattern of small rotations depicted in Fig. 4 would have changed. However, if vectors fit small concentric circles in a given reference frame, they also fit small concentric circles in another reference frame. Thus, the pattern of small circles is function of the reference frame in terms of position of centre

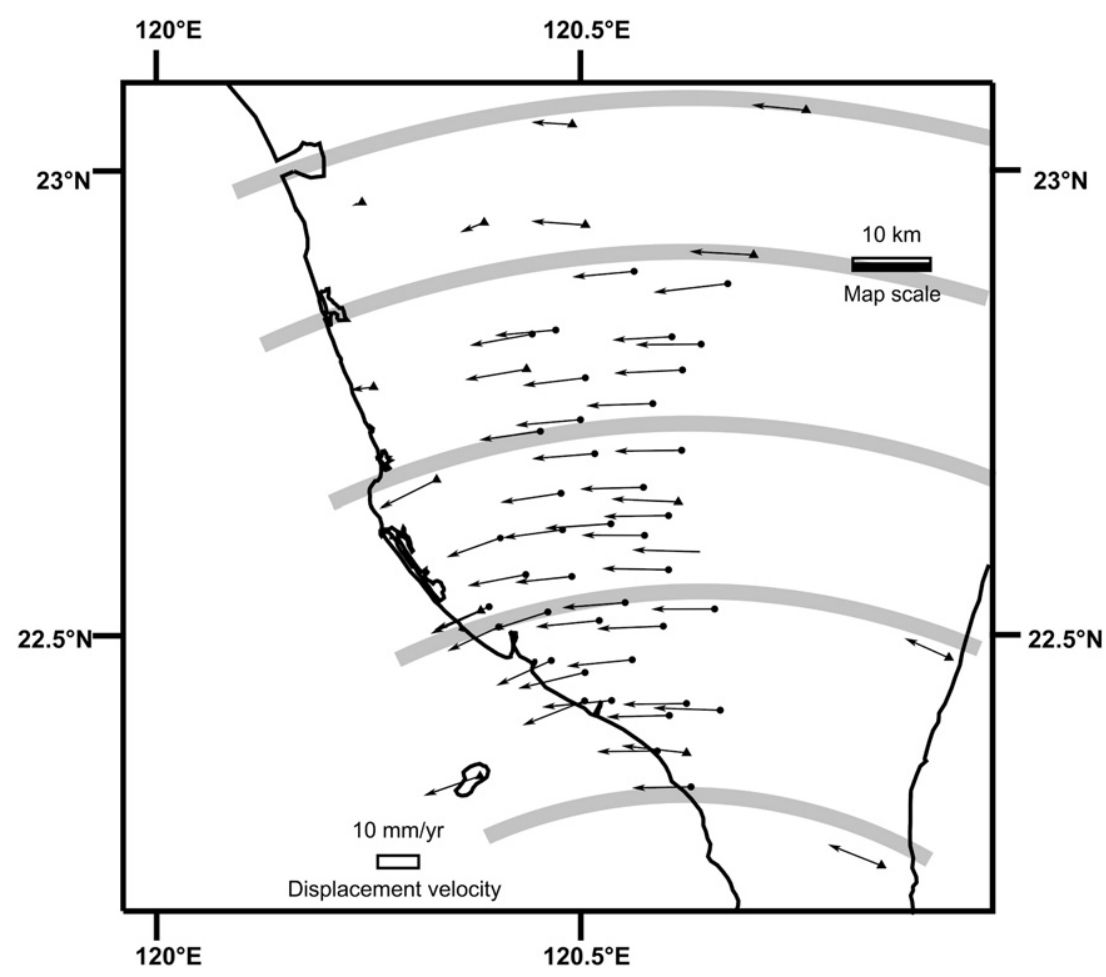

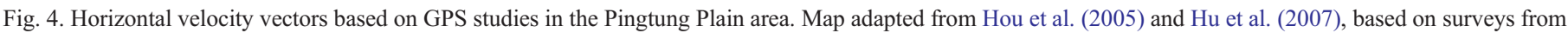

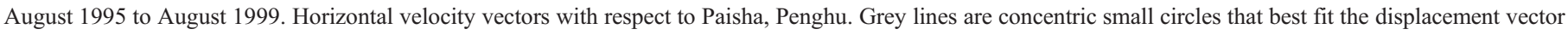

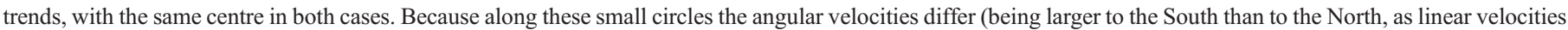

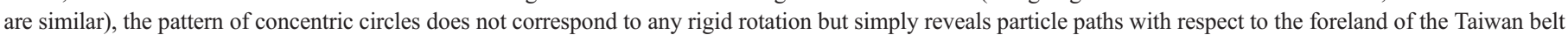
(see text). 
and amount of rotation, not in terms of the existence of bestfitting circles. These paths are drawn with respect to the stable foreland of the Taiwan belt, because the horizontal displacement vectors of the GPS network have been calculated in a frame involving a fixed position of station S01R in the Paisha Island (Penghu archipelago, Taiwan Strait) and a fixed direction from Paisha to Taipei (Hou et al., 2005; Hu et al., 2007).

We conclude that the present-day displacement in this Pingtung-Kaohsiung region of SW Taiwan cannot be interpreted in terms of rigid rotation. The particle displacement paths, however, follow circular trajectories around a common centre (Fig. 4). The displacement pattern thus resembles a flow of particles in a deforming medium, moving towards an open edge to the Southwest. Accordingly, the smallest velocities are found to the Northwest (near $22.8^{\circ} \mathrm{N}-120.3^{\circ} \mathrm{E}$, within and close to the stable foreland of the belt), whereas the largest velocities are found in the southern coastal Plain area (near $22.4^{\circ} \mathrm{N}-$ $120.4^{\circ} \mathrm{E}$, in the Kaohsiung district) and point towards the WSW. The general displacement towards the WSW in the coastal Pingtung Plain markedly contrasts with the movement towards the WNW that generally prevails in the Foothills of Taiwan.

Because no large earthquake occurred within the Pingtung Plain area during the survey period, one may question the significance of the horizontal displacement velocity pattern of Fig. 4 in terms of long-term deformation. This pattern simply reflects the inter-seismic deformation during the short period of the GPS survey. The problem of the relationship between coseismic and inter-seismic deformation can be better addressed in the case of the Ilan Plain region, where large earthquakes occurred during survey periods.

\subsection{The Ilan Plain area}

In the Ilan region, our earliest data came from a work by Hsu (1998), based on GPS surveys carried out from 1992 to 1996 with similar techniques as for the Pingtung GPS Network. The distance variations were actually measured along baselines inside the local network. The resultant velocity field was referenced by permanent GPS stations near Ilan, controlled by the ITRF (International Terrestrial Reference Frame). The results were displayed in two main reference systems: the ITRF96 global frame and a frame attached to the Shangai station, South China (Hsu, 1998). Uncertainties resulted from local baseline precision for relative displacements. The ITRF systematic uncertainty was involved when calculating displacements in the global frame. Hsu also provided tables of displacements with respect to Shangai station. Because the displacement of Shangai with respect to the Penghu Islands is small, the corresponding pattern of horizontal velocities resembles that obtained in the Penghu reference frame that we adopted. As mentioned before, such a reference highlights the displacements relative to the Chinese shelf, that is, the foreland of the Taiwan collision zone.

Near Ilan, low velocities could be expected in comparison with the Pingtung Plain, because the collision is by far less active in the Ilan area than in SW Taiwan. This difference results from the propagation of the collision towards the $\mathrm{SW}$, as pointed out by Suppe (1984). However, the GPS surveys in the Ilan Plain area revealed rather high velocities, up to $3-4 \mathrm{~cm} / \mathrm{yr}$. This surprising contrast suggests that the velocity pattern in the Ilan region is strongly influenced by the adjacent system of the
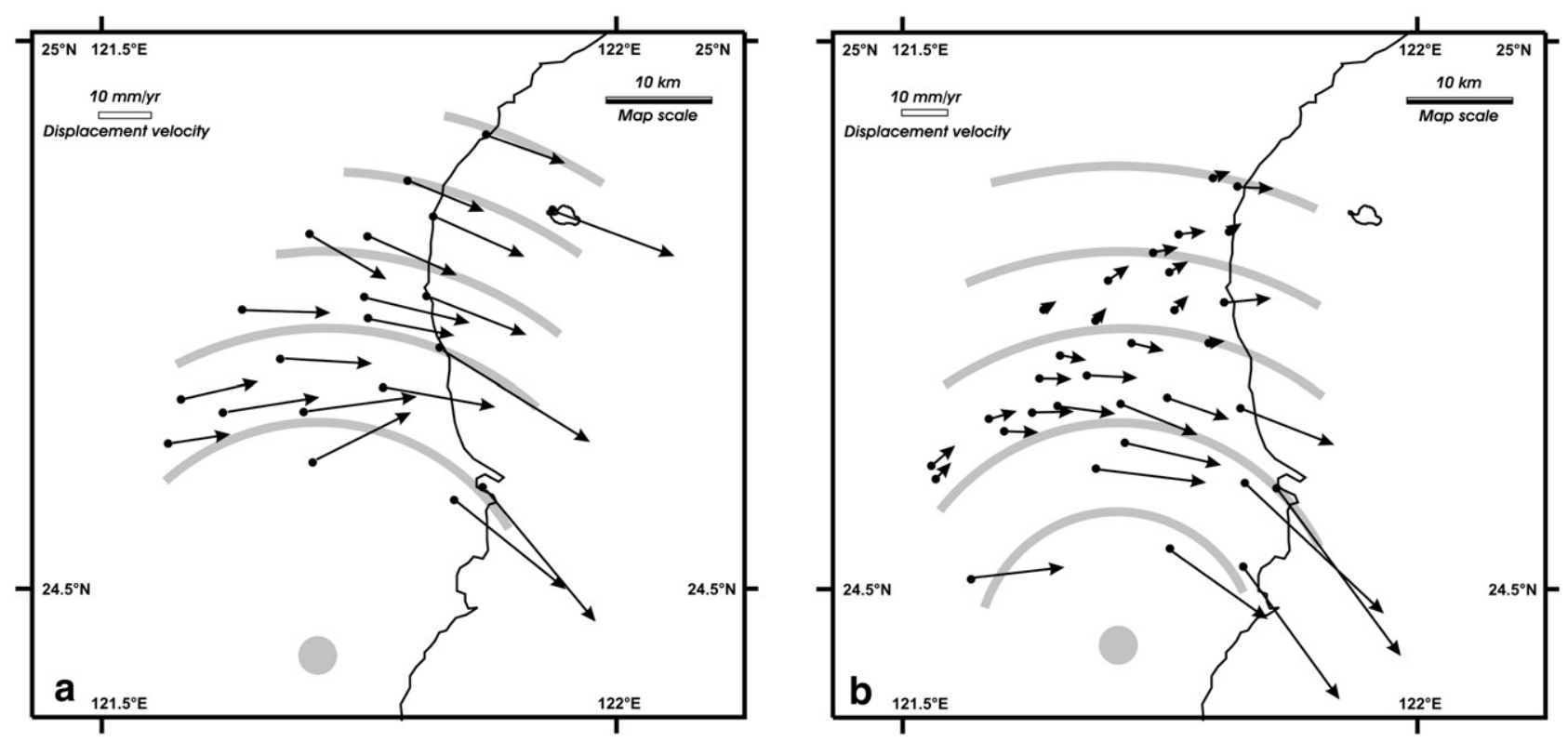

Fig. 5. Horizontal velocity vectors from GPS studies in the Ilan Plain area. (a) Map of velocity vectors adapted from Hsu (1998), based on surveys from 1992 to 1996. Horizontal velocity vectors within a frame attached to the Shangai station (South China), which shows relatively little displacement with respect to the Taiwan Strait and Penghu Islands. (b) Map of velocity vectors adapted from Hu et al. (this issue), based on surveys from October 2002 to December 2005 . Horizontal velocity vectors with respect to Paisha, Penghu (as for Fig. 4). Grey lines are concentric small circles that best fit the displacement vector trends. Note that within the range of uncertainties the centre (grey dot) is the same in both cases. Along these small circles velocities markedly differ. Also, they are larger to the South than to the North, whereas constant angular velocity would imply linear velocities increasing towards the North. Thus, the pattern of concentric circles does not reflect any rigid rotation but simply indicates the particle paths with respect to the Taiwan belt foreland (see text). 
Ryukyu trench, arc and back-arc system, because velocities can hardly be attributed to the collision zone of northern Taiwan, where the present-day convergence rate is low. Based on levelling studies since 1985, Liu (1995) concluded that the Ilan Plain is an actively subsiding onland extension of the Okinawa Trough, as proposed by several authors (e.g., Tsai, 1986). Liu determined high values of subsidence rate (about $20 \mathrm{~mm} / \mathrm{yr}$ in the axis of the subsidence area) and tilt rate $(0.44 \mu \mathrm{radian} / \mathrm{yr}$ towards the East).

The simplified map of horizontal velocities resulting from Hsu's work (1998) shows that the largest velocities are oriented towards the Southeast (Fig. 5a). In the frame attached to South China (Shangai), and hence subject to little displacement with respect to the Penghu Islands, the contraction related to plate convergence would imply displacements towards the Northeast, opposite to the observed directions. Despite few local discrepancies, a good fit could be found between the velocity vector trends and series of small circles (in grey in Fig. 5a). The small circles that best fit the vector trends have a common centre approximately located near $24.4^{\circ} \mathrm{N}-121.7^{\circ} \mathrm{E}$. However, the velocities in the Ilan Plain do not increase towards the north proportional to circle radius, as should be the case for a rigid rotation. On the contrary, these velocities rapidly increase towards the south (that is, towards the centre of the small circles). This pattern reveals a non-rigid rotation, like that of the Pingtung Plain (compare Figs. 4 and 5). However, in Ilan, the rotation is clockwise in sense.

Based on earlier geodetic monitoring, Liu (1995) proposed that the south edge of the Ilan Plain undergoes a clockwise rotation of $1.3 \mu \mathrm{radian} / \mathrm{yr}$. Our kinematic determination is in agreement with this conclusion concerning the sense of rotation. With the horizontal velocity pattern of Fig. 5a and our bestfitting centre of rotation (relative to the Taiwan belt foreland), the maximum angular velocity is obtained near the southeast corner of the Ilan Plain, where the linear velocity is approximately $30 \mathrm{~mm} / \mathrm{yr}$ at a distance of about $20 \mathrm{~km}$ from the centre. The corresponding angular velocity is $1.5 \mu \mathrm{radian} / \mathrm{yr}$, consistent with Liu's determination. However, this value is a maximum that cannot be extrapolated because the rotation is not a rigid one. The angular velocities vary and rapidly decrease on land towards the West as well as the North.

We therefore point out that in the Ilan Plain area, as for the Pingtung Plain, the small circles of Fig. 5 simply reveal the approximate path of particles with respect to the stable foreland of the Taiwan belt. While comparing the Ilan and Pingtung domains, however, three differences deserve attention. First, the senses of the non-rigid rotations are opposite (clockwise for Ilan, anticlockwise for Pingtung). Second, the size of the affected area is smaller in NE Taiwan (about $35 \mathrm{~km}$ along the $\mathrm{N}-\mathrm{S}$ direction for the Ilan Plain area, instead of more than $70 \mathrm{~km}$ for the Pingtung Plain). Third, marked contrasts exist between the two studied areas for both the trends and the velocities: the increase in velocity from North to South across the Ilan Plain is larger and takes place over a smaller distance, while more pronounced vector trend changes occur (compare Figs. 5a and 4).

In addition to the 1992-1996 GPS results presented by Hsu (1998), we analysed more recent data from $\mathrm{Hu}$ et al. (this issue), based on GPS surveys from October 2002 to December 2005. Note that a time gap of about six years existed between these two survey periods (1992-1996 and 2002-2005). Some differences between the two successive displacement patterns are obvious. Especially, the 2002-2005 survey (Fig. 5b) shows a more pronounced contrast in horizontal velocities across the Ilan Plain area than the 1992-1996 survey (Fig. 5a). This difference between the velocity results may seem surprising. However, considering the existence of the seismic cycle and the occurrences of large earthquakes near Ilan during these periods, we think that the difference between the velocity field vectors of Fig. $5 \mathrm{a}$ and $\mathrm{b}$ probably results from actual changes in instantaneous deformation, rather than from technical problems in GPS processing.

A simple geometrical observation supports our hypothesis. Fig. 6 shows the horizontal velocity field obtained after uniform subtraction of an ESE-pointing vector (that is, a WNW-pointing vector is added) of nearly $1 \mathrm{~cm} / \mathrm{yr}$ in Fig. 5a. The vector pattern thus obtained resembles that of the 2002-2005 survey (compare Figs. 5b and 6). Assuming that in both cases no technical positioning error with respect to reference frames has affected the GPS processing and that a single major seismic crisis has occurred in the Ilan region during the surveys periods, this comparison would bring constraints on co-seismic displacement. It would imply that in addition to the interseismic displacement the Ilan area would have been affected by a coseismic displacement towards the ESE as large as $4-5 \mathrm{~cm}$ during the 1992-1996 survey period, or a co-seismic displacement towards the WNW as large as about $3 \mathrm{~cm}$ during the 2002-2005 survey period.

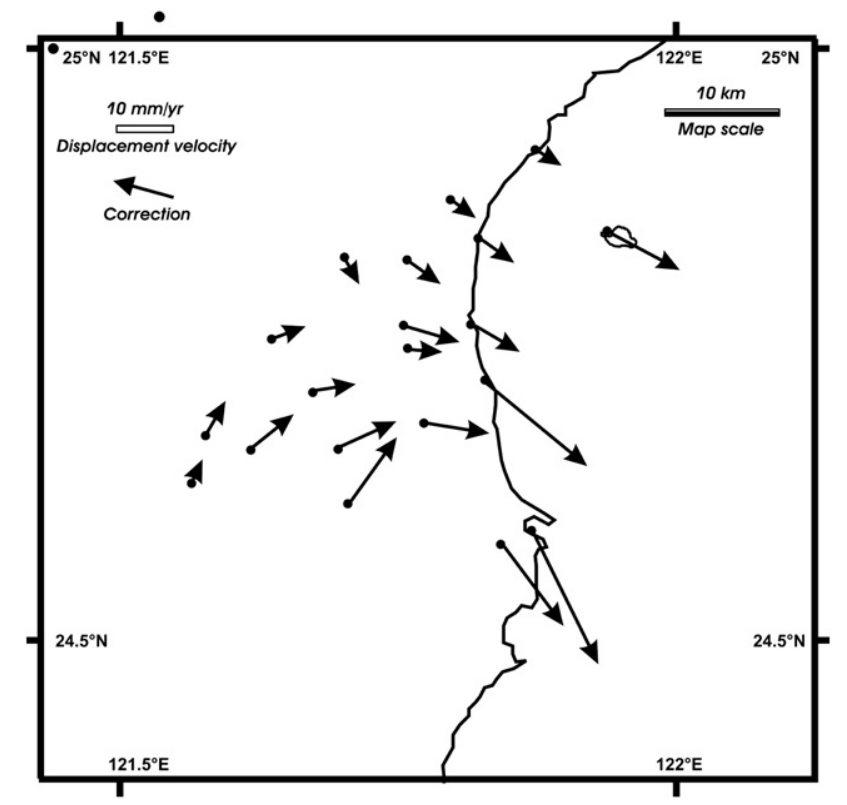

Fig. 6. Horizontal velocity vectors in the Ilan Plain area, with respect to the Hsuehshan Range of northern Taiwan, 1992-1996 survey period (derived from Hsu's GPS results, 1998). Two stations near the northwest corner of the quadrangle (shown as small black dots) have been adopted as reference frame. As a result, a WNW-directed displacement vector of about $1 \mathrm{~cm} / \mathrm{yr}$ was added to the displacement vectors of Fig. 5a. Note that the resulting displacement pattern resembles that of the 2002-2005 survey period (compare with Fig. 5b). 
The graph of Fig. 7 illustrates the evolution of the seismicity in and around the Ilan region from 1992 to 2006, based on Central Weather Bureau (CWB) records. Considering earthquakes of magnitude 6 and larger, shallow events occurred onshore and offshore near Ilan in 1994 (June 5th, $M=6.2$ ) and 1995 (June 25th, $M=6.5$ ) during the first survey, and in 2004 (November 11th, $M=6.1$ ) and 2005 (March 5th, $M=6.0$ ) during the second survey. Deeper events occurred offshore in 1994 (February 1st, $M=6.1$ ) and 1996 (July 29th, $M=6.1$ ) during the first survey, and in 2004 (October15th, $M=7.1$ ) and 2005 (June 1st, $M=6.0$ ) during the second survey. Eleven large earthquakes occurred within the dotted quadrangle of the map of Fig. 7 between the two survey periods, including two offshore earthquakes of magnitude 6.8 in 2002 that correspond to the second step in the graphs of Fig. 7. Interestingly, the two shallow earthquakes that occurred near Ilan during the first survey (June 5th, 1994 and June 25th, 1995) were both compatible with NW-SE extension and NE-SW compression, according to earthquake focal mechanisms determined by Kao and Jian (1999). Therefore, a possibility exists that these earthquakes account for the additional displacement towards the ESE revealed by the 1992-1996 survey with respect to the 2002-2005 one.

However, large earthquakes also occurred in the Ilan region during the second GPS survey (Fig. 7), with a variety of focal mechanisms. Large earthquakes in 2002, soon before the beginning of this second survey, may even have affected displacement as a result of post-seismic creep. Such behavior has recently been highlighted by Lee et al. (2006) along the Chihshang Fault of the Longitudinal Valley, the active suture zone between the Philippine Sea plate and Eurasia (Fig. 1). Post-seismic creep affected the surface trace of the fault during the months following the 2003, Mw=6.5, Chengkung earthquake in eastern Taiwan. This example shows that the possibility of delayed surface response to co-seismic displacement deserves attention while analysing surface deformation by geodetic means.

In any case, the earthquake occurrence distribution in the studied area is complex in space, time and mechanisms. This complexity precludes drawing firm conclusions about the origin of the difference between the patterns of Fig. 5a and b. Whether or not such a vector difference corresponds to major earthquakes should be revealed by data from permanent recording stations with reference to external frames (such as ITRF or S01R), indicating actual differences between co-seismic and inter-seismic displacements. The local networks that we used rather aimed at providing high accuracy in relative displacements and dense local coverage (Hsu, 1998; Hou et al., 2005, 2009; Hu et al., 2007 and this issue). In our analysis, we consequently focused on integrating strain in the study areas, regardless of the origin of the displacements (co-seismic and inter-seismic), although the recording periods are too brief to smooth the effects of the seismic cycle.

Regardless of these problems, a striking analogy exists between the distributions of displacement velocity trends expressed in terms of best-fitting small circles in Fig. 5. Linear velocities markedly differ, but taking velocity trends into sole account the centre of the best-fitting circles was found to be the same within the range of uncertainties (compare Fig. 5a and b). Comparison between Figs. 5a and 6 would be more correct; because the displacement correction from Fig. 5b to Fig. 6 is smaller than uncertainties in the position of best-fitting circles there is no need to discuss it. This consistency, despite the presence of large earthquakes during the survey periods,

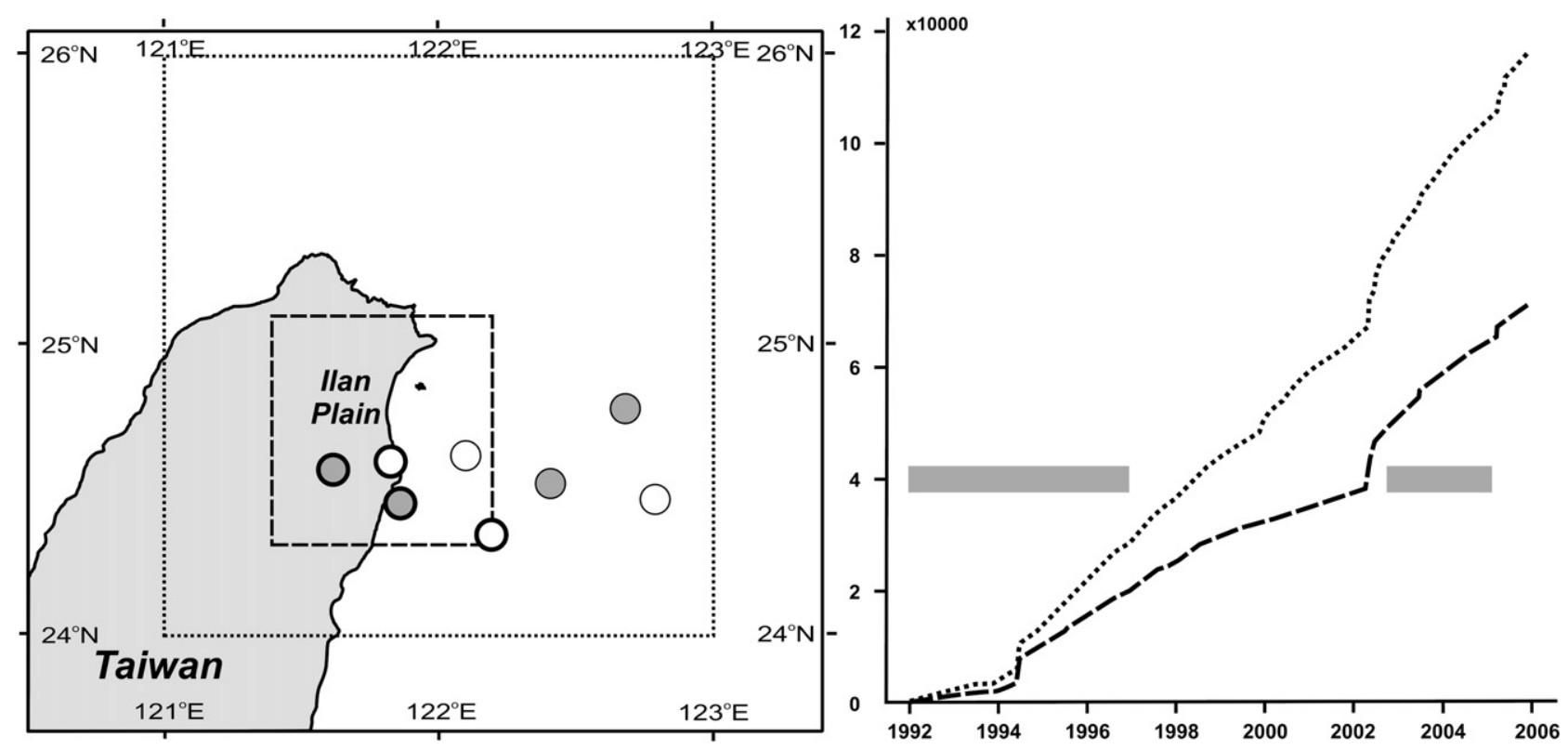

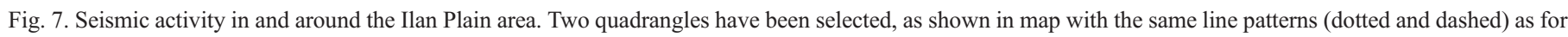

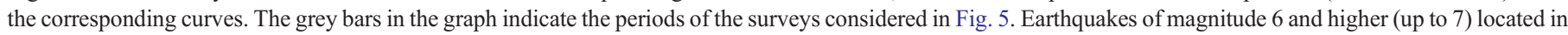

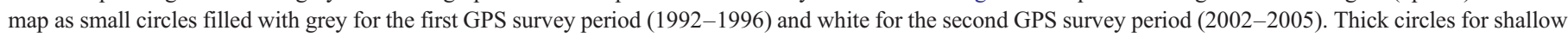
earthquakes (0-40 km in depth), thin circles for deeper earthquakes. Earthquakes between the two survey periods are not shown. 
suggests that the displacement trajectory trends (shown relative to Taiwan foreland) have strong geodynamic significance regarding the deformation of the Ilan Plain area.

We conclude that the pattern of displacement vectors in and around the Ilan Plain is in the first approximation compatible with small circles, but cannot fit a rigid rotation and resembles a particle flow moving towards the southeast in a deforming medium. Thus, the small circles drawn in Figs. 4 and 5 have some value to indicate average particle paths. Also, the general displacement towards the ESE that affects the Ilan Plain area contrasts with the movement towards the northwest that prevails in eastern and northern Taiwan.

\subsection{Displacement patterns and extrusion}

As discussed above, the geodetic results presented in Figs. 4-6 deserve careful interpretation in light of the seismic cycle concept. In the Ilan region, the displacement patterns obtained for the periods 1992-1996 and 2002-2005 markedly differ (Fig. 5). This difference, which is far beyond technical uncertainties in GPS analyses, suggests that important changes occurred, probably influenced by large earthquakes.

Despite such reservations, the displacement patterns observed in NE and SW Taiwan reveal a particular distribution, summarised in Fig. 8. The radius of the small circles that fit the trends of horizontal velocity vectors is $2-3$ times larger in the

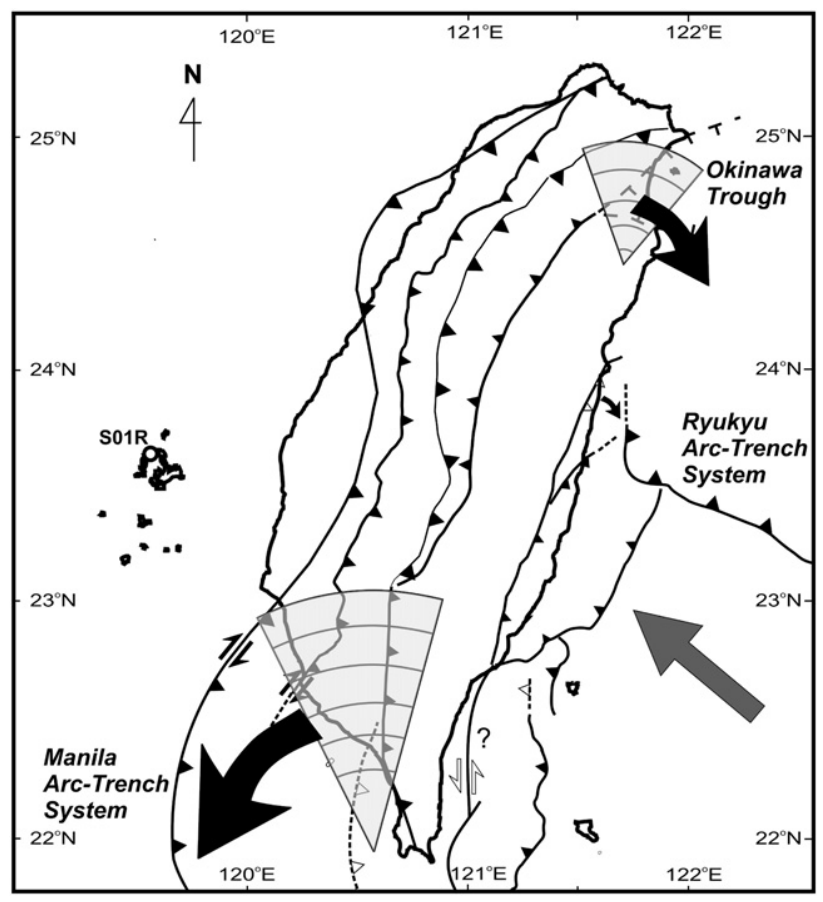

Fig. 8. Location of the extrusion of the Pingtung and Ilan Plains within the frame of the Taiwan collision. In light grey, small circles tangent to displacement velocity vectors. These circles suggest particle paths, but do not reveal any rigid rotation (see text and captions of Figs. 4 and 5). Large black arrows indicate paths of extrusion and related senses of rotation. Other symbols as in Fig. 1. Permanent station S01R (Penghu Islands, Taiwan Strait) of the Taiwan GPS network (Yu et al., 1997) shown as open dot (reference in geodetic analysis of Figs. 4 and 5).
Pingtung Plain area (approximately from 50 to $135 \mathrm{~km}$ from $\mathrm{S}$ to $\mathrm{N}$ ) than in the Ilan Plain area (approximately from 12 to $50 \mathrm{~km}$ from $\mathrm{S}$ to $\mathrm{N}$ ).

In the Ilan Plain area, according to the 1992-1996 displacement pattern of Fig. 5a, the angular velocity in degrees/yr ranges between $210^{-5}$ (for the largest distance to centre, $52 \mathrm{~km}$ ) and $7.510^{-5}$ (for the smallest distance to centre, $22 \mathrm{~km}$ ). The clockwise angular velocities indicated by the 2002-2005 displacement pattern of Fig. 5b reveal higher contrast, from about $0.510^{-5}$ (for the largest distance to centre, $49 \mathrm{~km}$ ) to $1410^{-5}$ (for the smallest distance to centre, $10 \mathrm{~km}$ ), also in degrees/yr. These contrasts reveal the large amount of left-lateral shear that occurs in the horizontal plane, within the deforming area being extruded towards the SE. Taking into the distribution of stations and the velocity variations in the pattern of displacement vectors, one or two major faults hardly explain this pervasive left-lateral shear: the presence of a larger number of faults is more likely.

In the Pingtung Plain area, the anticlockwise angular velocities revealed by the 1995-1999 displacement pattern of Fig. 4 are smaller on average. In degrees/yr, the angular velocity ranges between $0.510^{-5}$ at a distance of about $135 \mathrm{~km}$ north of the centre and $1.5-210^{-5}$ at a distance of about $50 \mathrm{~km}$. On average, the angular velocities are much smaller for the Pingtung Plain than for the Ilan Plain. This difference is a consequence of the larger along-belt dimension of the domain affected (more than $85 \mathrm{~km}$ for Pingtung, less than $38 \mathrm{~km}$ for Ilan), the smaller maximum displacement observed (about $1.5 \mathrm{~cm}$ for Pingtung, about $3 \mathrm{~cm} / \mathrm{yr}$ for Ilan) and the smaller average distance to the centre of small circles (90-95 km for Pingtung, about $30 \mathrm{~km}$ for Ilan). Thus, the difference in angular velocity also implies internal shear in the deforming area being extruded, knowing that extrusion occurs towards the SW and shear is right-lateral in the Pingtung region. The distribution of stations and the velocity variations in the pattern of displacement vectors clearly suggest that more than one or two major faults are necessary to accommodate this pervasive right-lateral shear. Note that the shear rate is much smaller for Pingtung than for Ilan, because it is distributed over a larger area while velocities are smaller.

These comparisons deserve comments. The results of the 1992-1996 and 2002-2005 geodetic surveys near Ilan reveal significant differences in horizontal velocities (Fig. 5), suggesting that any discussion in terms of amplitudes deserves care (a reasonable reservation considering the earthquake cycle). Acknowledging the major role of the 1999 Chichi earthquake at the scale of almost the entire Taiwan belt, the most appropriate comparison between velocity patterns at both tips of the Taiwan belt is that of the 1992-1996 and 1995-1999 surveys (Ilan and Pingtung respectively, Figs. 4 and 5a). Because of these limitations, our discussion will focus on orientations rather than magnitudes. To this respect, it is encouraging to observe that despite obvious quantitative differences the velocity patterns of Fig. 5a and b (same Ilan area before and after a major earthquake in the adjacent collision belt) fit the same small circles and show the same differential trend. 


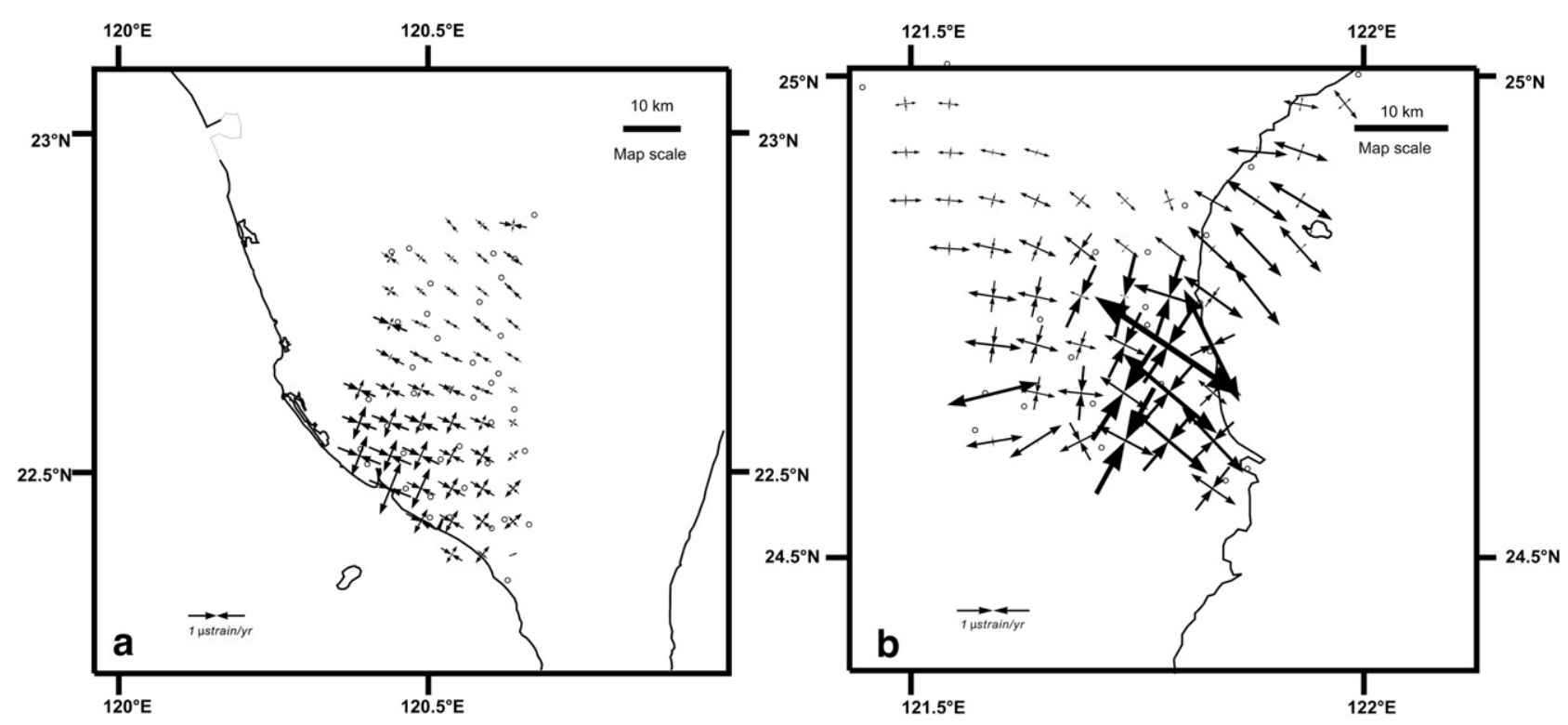

Fig. 9. Deformation patterns in the Pingtung Plain region of SW Taiwan (on left) and the Ilan Plain region of NE Taiwan (on right). Same data and geographic frames as in Fig. 1. Small grey dots indicate GPS stations. Convergent and divergent pairs of arrows indicate maximum horizontal shortening and lengthening, respectively.

As Fig. 8 shows, the senses of rotation are opposite at both tips of the belt and the extrusion occurs in both cases away from the collision zone. The senses of shear are also symmetrical although their directions are not. Differences however alter this symmetry and deserve consideration. First, the displacement in both cases increases towards the South, that is farther from the collision zone in Pingtung and closer to it in Ilan. Second, the escape occurs towards the external zones of the belt (to the SW) in Pingtung but towards the internal zones (to the SE) in Ilan. Before examining these differences, it is necessary to derive the strain and stress regimes that prevail in these areas, based on the existing geodetic and seismological information.

\section{The present-day horizontal deformation}

Velocity field gradients deserve attention. Using the horizontal displacement data summarised and interpreted in Section 3 (Figs. 4 and 5a), we calculated horizontal strain rate tensors in the corresponding areas. Contrary to displacements velocity fields displayed in the previous Section (Figs. 4 and 5), the strain rate analyses presented in this Section are not affected by the choice of spatial GPS reference. The strain analysis method is the same as that previously employed at the scale of the whole Taiwan Island (Chang et al., 2003). First, the interpolation of velocity data allows determining velocity vectors at each node of a square mesh grid. Second, the horizontal strain rate tensor is calculated for each mesh, based on consideration of the surrounding vectors. The result is a map of horizontal principal axes (Fig. 9). A reasonable square mesh size has been chosen based on the density of GPS information. The areas where extrapolation is unreliable outside the dense network have been left blank.

In the northern Pingtung Plain, the pattern of horizontal strain rate tensors unambiguously reveals NW-SE contraction, with no or little deformation in the NE-SW direction (Fig. 9a). The southern Pingtung Plain area is dominated by WNW-ESE contraction and NNE-SSW elongation. In terms of relative amplitudes, a limited increase in contraction rate and a very large increase in elongation rate exist towards the Southwest. It follows that to the North the horizontal deformation regime involves compression with little or no extension, whereas to the South it involves both compression and extension. In terms of amplitude, the NNE-SSW elongation is significantly larger than WNW-ESE contraction in the coastal area near $22.5^{\circ} \mathrm{N}-$ $120.4^{\circ} \mathrm{E}$. Knowing that earthquake focal mechanisms of strikeslip and normal types are present in this area (as mentioned in

Table 1

Main properties of earthquakes analysed, Ilan Plain area

\begin{tabular}{|c|c|c|c|c|c|c|c|c|}
\hline Subset & Figure & Number & \multicolumn{3}{|l|}{ Magnitude } & \multicolumn{3}{|c|}{ Depth (km) } \\
\hline Strike-slip & $10 \mathrm{a}$ & 33 & 3.5 & 6.0 & 4.1 & 12 & 60 & 24 \\
\hline Normal 2 & $10 \mathrm{c}$ & 13 & 3.4 & 5.0 & 4.1 & 11 & 45 & 22 \\
\hline Normal 3 & $10 \mathrm{~d}$ & 6 & 3.6 & 4.7 & 4.0 & 21 & 92 & 36 \\
\hline Reverse & 11 & 44 & 3.4 & 5.6 & 4.2 & 13 & 118 & 40 \\
\hline
\end{tabular}

Source of data: BATS, Academia Sinica, Taipei. Three types distinguished based on largest slip component (normal, strike-slip or reverse). 8 oblique-slip earthquakes not mentioned. The three subsets of normal type mechanisms correspond to NW-SE, N-S and E-W general trends of extension (subsets 1, 2 and 3 respectively). 

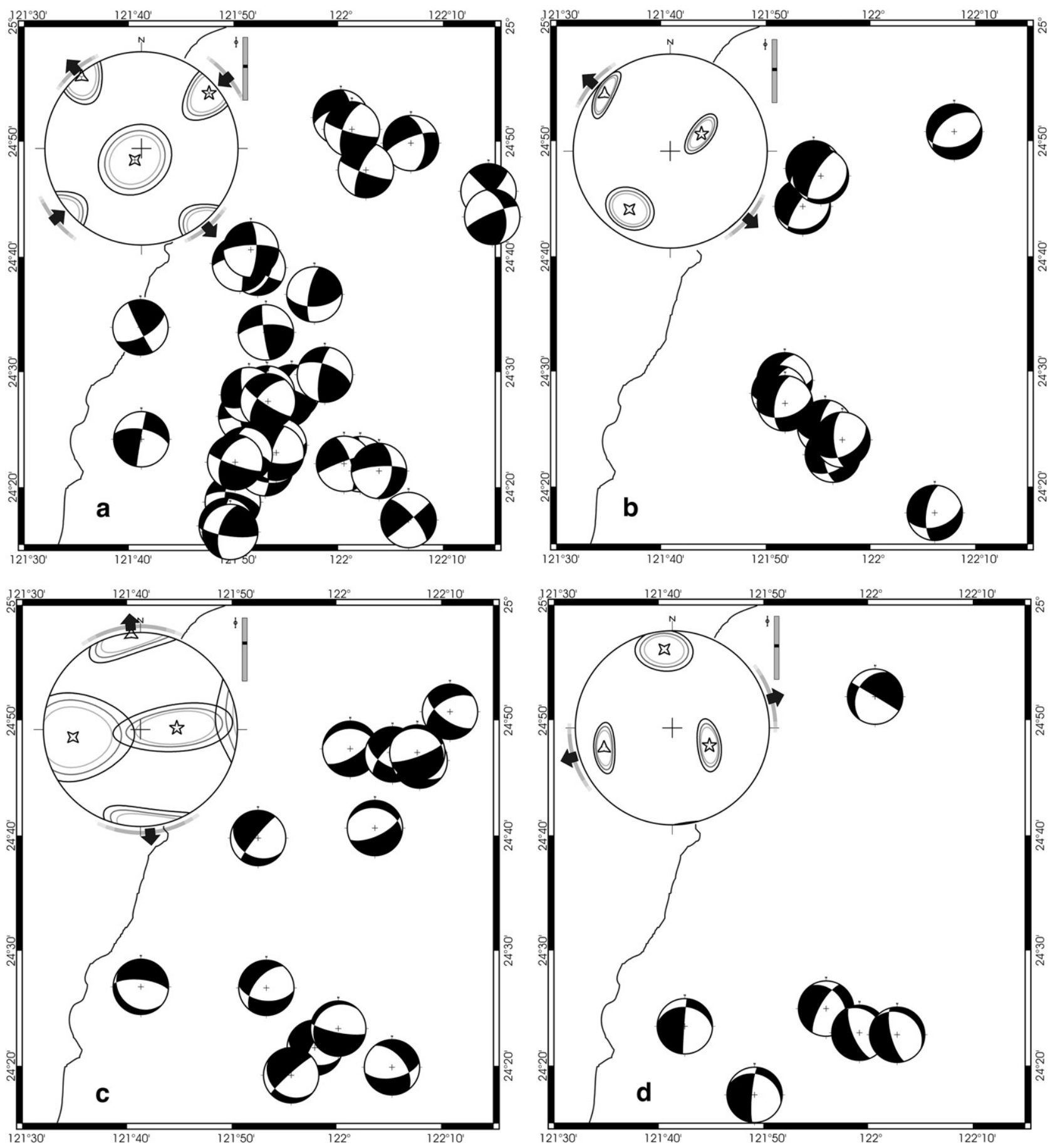

Fig. 10. Main results of stress inversion of focal mechanisms of earthquakes for the Ilan Plain area. (a) strike-slip type earthquakes, (b) normal-type earthquakes in agreement with NW-SE extension, (c) normal-type earthquakes in agreement with $\mathrm{N}-\mathrm{S}$ extension, (d) normal-type earthquakes in agreement with E-W extension. Separation between the three subsets of normal-type mechanisms has been made using a dynamic clustering method (as explained in Angelier, 1984) applied to the SSSC inversion for focal mechanisms (Angelier, 2002). Seismological data obtained from the BATS system. Double couple focal mechanisms shown as usual 'beachball' stereoplots (equal-are projection of lower hemisphere, with compression dihedra in black and extension dihedra in white). At upper-left corner of each map, the steroplot (Schmidt's projection, lower hemisphere) of the results is shown. Inverse method described by Angelier (2002). Axes $\sigma_{1}$ (maximum compressive stress), $\sigma_{2}$ (intermediate stress) and $\sigma_{3}$ (minimum stress) shown as five-branch star, four-branch star and three-branch star, respectively. Confidence ellipses also shown (60\%, $75 \%$ and $90 \%$ ). Pairs of large black arrows indicate the resulting directions of extension (divergent arrows) or compression (convergent arrows). Grey patterns around arrows indicate confidence intervals (increasingly darker for $90 \%, 75 \%$, and $60 \%)$. The value of the ratio of principal stress differences, $\Phi=\left(\sigma_{2}-\sigma_{3}\right) /\left(\sigma_{1}-\sigma_{3}\right)$, is indicated in black within a bar, from 0 (base) to 1 (top). Subset properties listed in Table 1, numerical information about stress tensors and inversion parameters listed in Table 2.

Section 5 of this paper), the deformation regime is clearly transtensional in this area (Fig. 9a). Moreover, considering the strain rate homogeneity in the northern Pingtung Plain, the difference between strain rates east and west of $120.5^{\circ} \mathrm{E}$ in the southern Pingtung Plain clearly indicates that in the horizontal plane right-lateral shear occurs along a NNE-SSW direction, a 
conclusion that was already formulated based on the displacement pattern of Fig. 4.

In contrast with the Pingtung Plain case, horizontal contraction without horizontal extension is absent in the Ilan Plain (Fig. 9b). In the horizontal plane, extension without contraction exists, especially in the northeast onshore/offshore Ilan Basin. Earthquake focal mechanisms of strike-slip type are present in this area (see Section 5 below). This threedimensional seismotectonic information is compatible with the pattern of horizontal deformation revealed by GPS studies. Most of the Ilan Plain domain is consequently characterised by strike-slip deformation regime, with $\mathrm{N}-\mathrm{S}$ to NE-SW trending contraction and $\mathrm{W}-\mathrm{E}$ to $\mathrm{NW}-\mathrm{SE}$ elongation. Because elongation clearly dominates contraction in the coastal area, the deformation regime is clearly transtensional in type.

Two main features prevail in this strain rate pattern: a general increase in elongation rates from West to East and a change in elongation trend from $\mathrm{W}-\mathrm{E}$ to NW-SE, also from West to East. Because of the difference between strain rates in the central and southern coastal areas of the Ilan Plain, and taking into account the relative homogeneity of strain states in the western area, one concludes that left-lateral shear should occur along a NW-SE direction, as could already be inferred from the displacement pattern of Fig. 5.

\section{The present-day seismotectonic stress}

To determine the states of seismogenic stress that prevail in the Ilan Plain and Pingtung Plain regions, we carried out stress inversion of focal mechanisms of earthquakes recorded by the BATS network (Broadband Array for Taiwan Seismology) and published by the Academia Sinica, Taipei (Kao et al., 1998; Kao and Jian, 1999, 2001; see also the website of the Data Management Center, Institute of Earth Sciences, Academia Sinica, http://bats.earth.sinica.edu.tw/). Because a minimum number of stations is required for focal mechanism determination, small magnitudes are excluded so that the number of focal mechanisms is low with respect to the number of earthquakes recorded by the CWB network (Central Weather Bureau, Taipei) for the same period. However, the BATS determinations can be regarded as of good quality, which would not have been the case had mechanisms of smaller magnitude earthquakes recorded by few stations been considered.

Our inversion of double couple focal mechanisms to derive the seismogenic stress has been made according to the method described in detail by Angelier (2002). The method, not presented again, involves analytical inversion of data according to the same mathematical technique as for fault slips (Angelier, 1990b). However, the criterion differs and was chosen to fit the requirements of double couple focal mechanisms. There is no need to make any choice between nodal planes prior to, or during the inversion (detailed explanation in Angelier, 2002). Because the stress regimes identified in the Ilan and Pingtung areas are heterogeneous, we also used a dynamic clustering method suitable for separation of mixed stress states. The principle of this separation has been described by Angelier
(1984) for fault slip data analysis, its application for earthquake focal mechanisms follows the same guidelines.

\subsection{The Ilan Plain area}

The Ilan Plain area is affected by many earthquakes (Table 1). We considered a quadrangle from $24.25^{\circ} \mathrm{N}$ to $25^{\circ} \mathrm{N}$ in latitude and $121.5^{\circ} \mathrm{E}$ to $122.25^{\circ} \mathrm{E}$ in longitude, corresponding to an area of about $6300 \mathrm{~km}^{2}$, as shown in Fig. 10. This quadrangle contains 115 focal mechanisms of earthquakes ranging from 3.4 to 6 in magnitude (4.2 on average), for a survey period from July 1995 to June 2003. The recorded depths range between 13 and $118 \mathrm{~km}$ (40 km on average).

The results of our determination of seismotectonic stress in the Ilan Plain area are presented in Table 2 and Figs. 10 and 11. As Table 1 shows, among the 107 focal mechanisms with marked strike-slip, normal or reverse character, 33 are strikeslip (Fig. 10a), 30 are normal (Fig. 10b, c and d) and 44 are reverse (Fig. 11).

Not surprisingly, the latter mechanisms reflect compression at the north-western tip of the Philippine Sea Plate (Fig. 11), which is not the main subject of this paper. We focussed our study on the normal and strike-slip earthquakes that may reflect extrusion.

The trend analysis suggested, and an automatic separation process confirmed, that three main subsets of normal-type earthquake coexist, compatible with NW-SE (Fig. 10b), N-S (Fig. 10c) and E-W (Fig. 10d) general trends of extension. The seismotectonic stress indicated by the inversion of the strikeslip type earthquakes (Fig. 10a, N120 ${ }^{\circ} \mathrm{E}$ azimuth of extension) involves NW-SE trending minimum stress, in good agreement with the extension indicated by one group of normal-type earthquakes (Fig. 10b, N131 ${ }^{\circ} \mathrm{E}$ azimuth of extension). We infer that these two regimes are probably closely related through a permutation between maximum and intermediate principal stresses, $\sigma_{1}$ and $\sigma_{2}$ respectively, a common phenomenon in brittle tectonics ( $\mathrm{Hu}$ and Angelier, 2004). This permutation implies a high ratio $\Phi$ between principal stress differences $[\Phi=$ $\left.\left(\sigma_{2}-\sigma_{3}\right) /\left(\sigma_{1}-\sigma_{3}\right)\right]$. Considering the earthquakes of the two sub-groups together (strike-slip, Fig. 10a and normal, Fig. 10b), the inversion effectively yielded a ratio $\Phi$ close to 1 . While processing these subsets separately (Table 2), lower ratios $\Phi, 0.5-0.6$, were obtained, because the main constraints on $\Phi$ values come from nodal planes at large angles with all principal stress axes (Angelier, 1984). In the present case, such planes are almost absent (nodal planes close to the $\sigma_{2}$ axis are numerous but cannot tightly constrain $\Phi$ ).

The seismotectonic stress indicated by the inversion of the other two subsets of normal-type earthquakes involves a $\mathrm{N} 175^{\circ} \mathrm{E}$ azimuth of extension for the largest subset (Fig. 10c) and a $\mathrm{N} 073^{\circ} \mathrm{E}$ azimuth of extension for the smallest one (Fig. 10d). These two regimes are probably related through a permutation between minimum and intermediate principal stresses, $\sigma_{3}$ and $\sigma_{2}$ respectively, which is also common in brittle tectonics (Hu and Angelier, 2004). The low number of earthquakes for these two subsets (12 and 5 respectively) precludes further investigation. This permutation implies a low 
Table 2

Results of stress inversion of focal mechanisms of earthquakes, Ilan Plain area

\begin{tabular}{|c|c|c|c|c|c|c|c|c|c|c|c|c|c|}
\hline \multirow[t]{2}{*}{ Fig. } & \multirow{2}{*}{$\begin{array}{l}\omega_{\mathrm{acc}} \\
(\%)\end{array}$} & \multirow[t]{2}{*}{$N_{\mathrm{acc}}$} & \multirow[t]{2}{*}{$N_{\text {rej }}$} & \multicolumn{2}{|c|}{$\sigma_{1}$ axis } & \multicolumn{2}{|c|}{$\sigma_{2}$ axis } & \multicolumn{2}{|l|}{$\sigma_{3}$ axis } & \multirow[t]{2}{*}{$\Phi$} & \multirow{2}{*}{$\begin{array}{l}\omega_{\mathrm{m}} \\
(\%)\end{array}$} & \multirow[t]{2}{*}{$\tau_{\mathrm{m}}(\%)$} & \multirow{2}{*}{$\begin{array}{l}\alpha_{\mathrm{m}} \\
(\mathrm{deg})\end{array}$} \\
\hline & & & & Trend & Plunge & Trend & Plunge & Trend & Plunge & & & & \\
\hline $10 \mathrm{a}$ & 45 & 26 & 7 & 51 & 11 & 210 & 79 & 320 & 4 & 0.54 & 75 & $83 \pm 11$ & $22 \pm 12$ \\
\hline $10 \mathrm{c}$ & 45 & 12 & 1 & 88 & 59 & 263 & 31 & 355 & 2 & 0.60 & 70 & $78 \pm 16$ & $22 \pm 14$ \\
\hline $10 \mathrm{~d}$ & 75 & 5 & 1 & 115 & 55 & 354 & 20 & 253 & 27 & 0.53 & 91 & $93 \pm 7$ & $11 \pm 7$ \\
\hline 11 & 55 & 27 & 17 & 115 & 25 & 207 & 3 & 304 & 65 & 0.61 & 74 & $82 \pm 11$ & $21 \pm 13$ \\
\hline
\end{tabular}

Rows correspond to subsets (Table 1) with corresponding map figure number: (10a) strike-slip, (10b) normal, NW-SE extension, (10c) normal, N-S extension, (10d) normal, E-W extension, (11) reverse. $\omega_{\text {acc }}$, minimum ratio omega requested for retaining a datum. $\omega$ may range from -100 (total misfit (to 100 (perfect fit). $N_{\text {acc}}$, number of accepted data (noted in terms of nodal planes). $N_{\text {rej }}$, number of rejected data. The orientations of principal stress axes $\sigma_{1}$ (maximum compressive stress), $\sigma_{2}$ (intermediate stress) and $\sigma_{3}$ (minimum stress) given in terms of trends and plunges, in degrees. $\Phi$, ratio of principal stress differences, $\Phi=\left(\sigma_{2}-\sigma_{3}\right) /\left(\sigma_{1}-\sigma_{3}\right)$. $\omega_{\mathrm{m}}$, average ratio omega of accepted data. $\tau_{\mathrm{m}}$, average dimensionless shear stress from 0 to $100 \%$ (average shear stress with respect to maximum shear stress). $\alpha_{\mathrm{m}}$, average angle between shear stress and slip, from 0 to $180^{\circ}$. The main estimator, $\omega$, and the two related subsidiary estimators, $\tau$ and $\alpha$, are obtained through consideration of both the nodal planes (a choice between nodal planes would result in better values, but has not been done). Complete explanation of the inverse method without choice of nodal planes by Angelier (2002).

ratio $\Phi$, which was effectively obtained while considering the earthquakes of these two sub-groups together. However, a low ratio $\Phi$ was not obtained after subset separation, for the same reason as discussed above.

The inversion of the reverse-type earthquakes reveals a WNW-ESE trend of compression, with a $\mathrm{N} 115^{\circ} \mathrm{E}$ azimuth for the maximum stress axis (Fig. 11). However, despite a reasonable fit demand (55\%, see Table 2), the rejection rate is high (17 earthquakes for a total of 44 reverse-type earthquakes). This relatively poor fit indicates heterogeneity in the reverse subset, which corresponds to different seismogenic units with contrasting mechanisms (e.g., Taiwan collision and Ryukyu subduction). Thus, the WNW-ESE direction of $\sigma_{1}$, although it fits very well the average trend of compression across most of the Taiwan belt, should be regarded as a kind of weighted average between three directions of compression (NW-SE, N-S and $\mathrm{E}-\mathrm{W}$ ). In this paper there is no need to discuss this compression in detail.

\subsection{The Pingtung Plain area}

The Pingtung Plain area is affected by much less earthquakes than the Ilan Plain area. We considered a quadrangle from 21. $5^{\circ} \mathrm{N}$ to $23.5^{\circ} \mathrm{N}$ in latitude and 119 to 121 in longitude, corresponding to an areas of about $45,500 \mathrm{~km}^{2}$. Despite it large extent, this quadrangle only contains 90 focal mechanisms of earthquakes (Table 3 ) ranging from 3.6 to 5.7 in magnitude (4.3 on average), for a survey period from October 1995 to June 2003. The recorded depths range between 11 and $60 \mathrm{~km}(19 \mathrm{~km}$ on average).

The results of our determination of seismotectonic stress in the Pingtung Plain area are presented in Table 4 and Fig. 12. The most numerous focal mechanisms are reverse in type. They simply reflect the compression in the Taiwan collision zone, but principally occur east and northeast of the Pingtung Plain, in the mountain belt (Fig. 12d). As a consequence, they do not actually reflect the main seismotectonic behaviour of this area.

Among the 50 remaining focal mechanisms, 34 are strikeslip in type (Table 3). Although visual separation based on trends of mechanisms is difficult, the automatic separation process already mentioned (using both the inversion described by Angelier, 2002 and the dynamic clustering algorithm presented by Angelier, 1984) revealed that two subsets coexist. The first, largest subset (27 earthquakes) is compatible with belt-perpendicular shortening (Fig. 12a). The corresponding trend of the maximum stress axis $\left(\mathrm{N} 124^{\circ} \mathrm{E}\right.$ azimuth of compression, Fig. 12a) resembles that obtained with reversetype focal mechanisms $\left(\mathrm{N} 110^{\circ} \mathrm{E}\right.$ azimuth of compression, Fig. 12d). This suggests that these two stress states correspond to a single seismotectonic stress regime through a permutation between minimum and intermediate principal stresses, $\sigma_{3}$ and $\sigma_{2}$ respectively. For the same reasons as before, the inversion of separate subsets provided relatively high $\Phi$ values $(0.5-0.6$, see Table 4), whereas a joint inversion yielded a low $\Phi$ value. Not

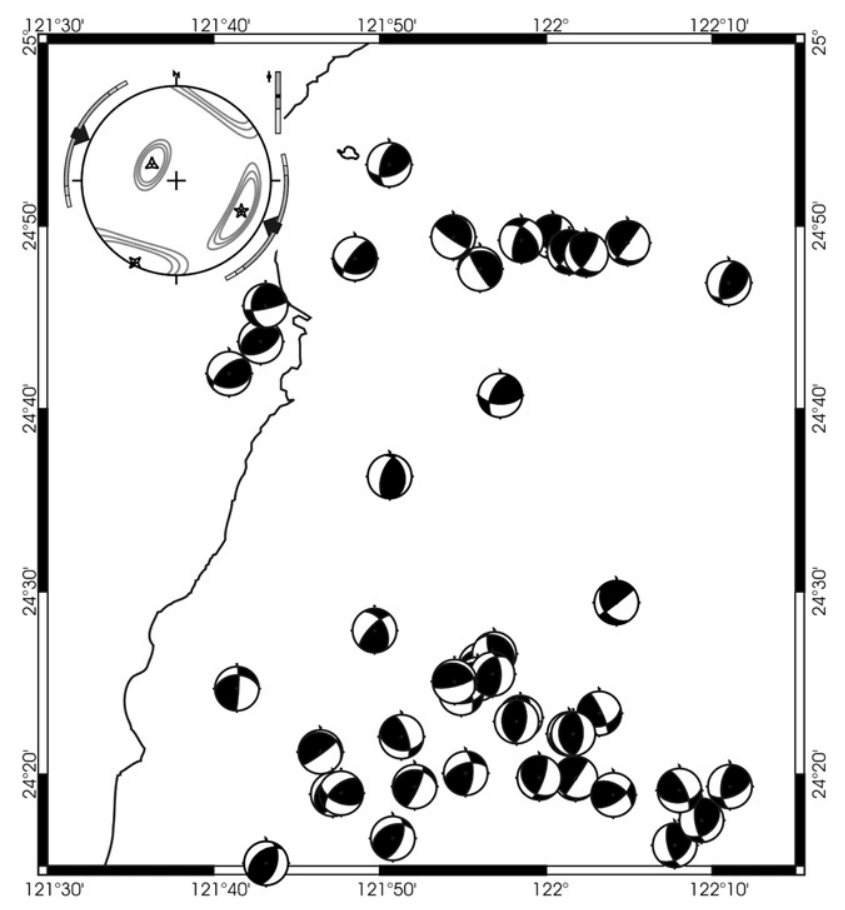

Fig. 11. Main results of stress inversion of focal mechanisms of reverse-type earthquakes for the Ilan Plain area. Explanation as for Fig. 10. See also Table 2. 
Table 3

Main properties of earthquakes analysed for the Pingtung Plain area

\begin{tabular}{|c|c|c|c|c|c|c|c|c|}
\hline \multirow[t]{2}{*}{ Subset } & \multirow[t]{2}{*}{ Figure } & \multirow[t]{2}{*}{ Number } & \multicolumn{3}{|l|}{ Magnitude } & \multicolumn{3}{|c|}{ Depth $(\mathrm{km})$} \\
\hline & & & Minimum & Maximum & Average & Minimum & Maximum & Average \\
\hline Strike-slip 1 & $12 \mathrm{a}$ & 27 & 3.6 & 5.7 & 4.3 & 11 & 26 & 15 \\
\hline Strike-slip 2 & $12 \mathrm{~b}$ & 7 & 3.6 & 4.6 & 4.2 & 11 & 60 & 26 \\
\hline Normal & $12 \mathrm{c}$ & 16 & 3.8 & 4.8 & 4.3 & 11 & 39 & 20 \\
\hline Reverse & $12 \mathrm{~d}$ & 40 & 3.6 & 5.2 & 4.2 & 11 & 54 & 19 \\
\hline
\end{tabular}

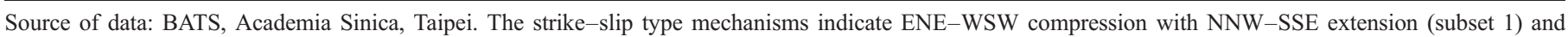
WNW-ESE compression with NNE-SSW extension (subset 2).

surprisingly, the mechanisms of Fig. 12a and d thus reflect the ESE-WNW compression across the Taiwan collision zone.

The second, smaller subset of strike-slip faults reveals NNW-SSE compression and WSW-ENE extension (N057 ${ }^{\circ} \mathrm{E}$ azimuth of extension, Fig. 12b). The remaining 16 focal mechanisms are normal in type and their inversion reveals a minimum stress axis that trends WSW-ENE (N061 ${ }^{\circ} \mathrm{E}$ azimuth of extension, Fig. 12c). Such a common trend of extension suggests that a stress permutation phenomenon (between $\sigma_{1}$ and $\sigma_{2}$ ) is present. Therefore, the stress states of Fig. 12b and Fig. 12c probably belong to a single regime dominated by WSW-ENE extension with a mixture of normal-type earthquakes and strike-slip earthquakes. As for the Ilan Plain, the inversion of the two subsets together yielded a ratio $\Phi$ close to 1, but the ratios $\Phi$ that we obtained for each subset, 0.5-0.6 (see Table 4), were poorly constrained because focal mechanisms are few and vary little in attitude.

The geographical distribution of epicentres supports our hypothesis of two major seismotectonic stress regimes respectively dominated by ESE-WNW compression and ENE-WSW extension. Considering the compression regime, despite a large number of data (67) in Fig. 12a and d, no related earthquake occurred beneath the Pingtung Plain. In contrast, among the few data (23) in Fig. 12b and c, three earthquakes occurred beneath the Pingtung Plain. The regime dominated by ESE-WNW compression prevails across the Taiwan belt, with two stress states inducing strike-slip and reverse-type earthquakes (Fig. 12a and d, respectively) and a permutation of $\sigma_{3} / \sigma_{2}$ type. The regime dominated by ENE-WNW extension affects the Pingtung Plain and its surroundings, with two stress states dominated by strike-slip and normal-type earthquakes (Fig. $12 \mathrm{~b}$ and c, respectively) and a permutation of $\sigma_{1} / \sigma_{2}$ type. The location being left apart, the normal-type earthquakes occurring in the Pingtung Plain and in the Central Range can hardly be distinguished, because their trends of extension are similar.

We conclude that in both the Ilan and Pingtung Plain areas, the stress analysis of focal mechanisms of earthquakes reveals local extensions (along NW-SE and ENE-WSW trends respectively), in addition to other regimes that could be expected in these areas, such as compressions and extensions directly related to convergence and back-arc opening. In both these cases, normal and strike-slip type earthquakes are closely associated within such particular extensional regimes, which therefore can be considered as transtensional in type.

\section{Discussion and conclusion}

The main results of our analysis are summarised in Fig. 8 for displacement and in Fig. 13 for strain and stress. The plate convergence along a SE-NW direction induces compression in the Taiwan mountain belt along ESE-WNW to SE-NW trends (seeSection 2). As summarised in Fig. 8 by pairs of grey arrows, the inversion of focal mechanisms of earthquakes of reverse type (with or without addition of compatible strike-slip mechanisms) revealed such an ESE-WNW trending compression in both the Ilan and Pingtung areas (despite reservations concerning Ilan, see Section 5). The counterclockwise deflection of the compression trend (ESE-WNW) with respect to convergence trend (SE-NW) across the Taiwan belt affects most of the collision zone. North of about $24.5^{\circ} \mathrm{N}$, this deflection decreases to zero and even becomes clockwise as a result of the fan-shaped trajectories of collision-related compression. This relationship between plate convergence and compression, which has been described and interpreted by Angelier et al. (1986), is also supported by simple finite-element models of the Taiwan collision zone (Hu et al., 1996). It results from the limited extent of the collision zone and the obliquity of

Table 4

Results of stress inversion of focal mechanisms of earthquakes for the Pingtung Plain area

\begin{tabular}{|c|c|c|c|c|c|c|c|c|c|c|c|c|c|}
\hline \multirow[t]{2}{*}{ Figure } & \multirow{2}{*}{$\begin{array}{l}\omega_{\mathrm{acc}} \\
(\%)\end{array}$} & \multirow[t]{2}{*}{$N_{\mathrm{acc}}$} & \multirow[t]{2}{*}{$N_{\text {rej }}$} & \multicolumn{2}{|l|}{$\sigma_{1}$ axis } & \multicolumn{2}{|l|}{$\sigma_{2}$ axis } & \multicolumn{2}{|c|}{$\sigma_{3}$ axis } & \multirow[t]{2}{*}{$\Phi$} & \multirow{2}{*}{$\begin{array}{l}\omega_{\mathrm{m}} \\
(\%)\end{array}$} & \multirow[t]{2}{*}{$\tau_{\mathrm{m}}(\%)$} & \multirow{2}{*}{$\begin{array}{l}\alpha_{\mathrm{m}} \\
\text { (deg) }\end{array}$} \\
\hline & & & & Trend & Plunge & Trend & Plunge & Trend & Plunge & & & & \\
\hline $12 \mathrm{a}$ & 60 & 27 & 5 & 304 & 12 & 67 & 69 & 210 & 17 & 0.60 & 99 & $88 \pm 10$ & $15 \pm 12$ \\
\hline $12 \mathrm{c}$ & 50 & 16 & 2 & 102 & 62 & 338 & 17 & 241 & 22 & 0.55 & 99 & $91 \pm 9$ & $13 \pm 13$ \\
\hline $12 \mathrm{~d}$ & 50 & 34 & 6 & 110 & 3 & 200 & 1 & 304 & 87 & 0.50 & 82 & $87 \pm 12$ & $16 \pm 11$ \\
\hline
\end{tabular}

Rows correspond to subsets (Table 3) with corresponding map figure number: (12a) strike-slip type earthquakes in agreement with WNW-ESE compression and NNE-SSW extension, (12b) strike-slip type earthquakes in agreement with NNW-SSE compression and ENE-WSW extension, (12c) normal-type earthquakes, (12d) reverse-type earthquakes. Other explanations as for Table 2. 

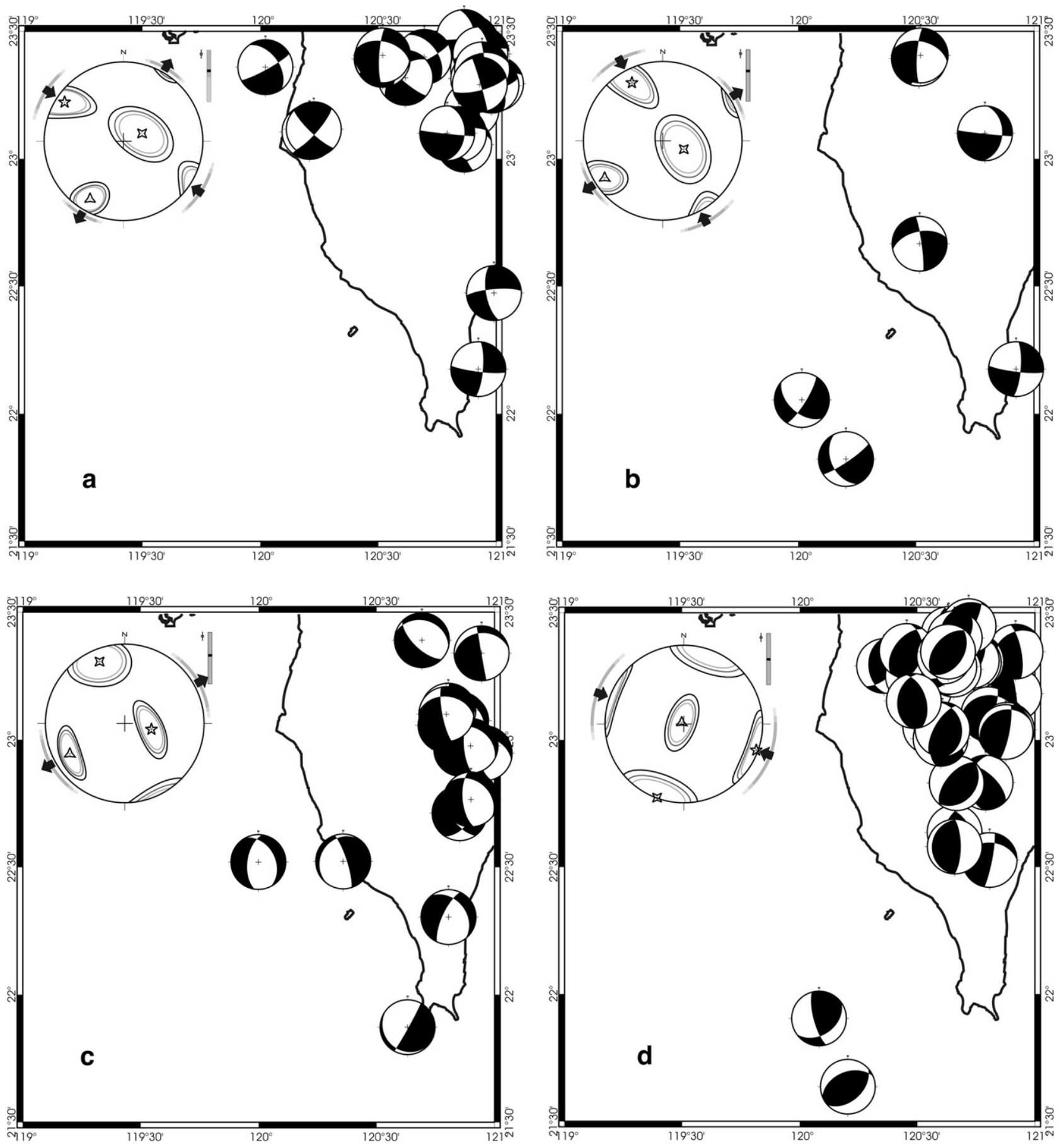

Fig. 12. Results of stress inversion of focal mechanisms of earthquakes for the Pingtung Plain area. (a) strike-slip type earthquakes in agreement with WNW-ESE compression and NNE-SSW extension, (b) strike-slip type earthquakes in agreement with NNW-SSE compression and ENE-WSW extension, (c) normal-type earthquakes. (d) reverse-type earthquakes. The separation between the two subsets of strike-slip type mechanisms has been made using a dynamic clustering method (as explained in Angelier, 1984) applied to the SSSC inversion for focal mechanisms (Angelier, 2002). Seismological data obtained from the BATS system. Other explanations as for Fig. 10.

the convergence with respect to plate boundary. Despite this general consistency, complex seismotectonic patterns prevail at both tips of the Taiwan mountain belt, as indicated by geodetic analyses of the present-day horizontal deformation (Section 4) and inversion of focal mechanisms of earthquakes in three dimensions (Section 5).
The significance of the geodetic information presented in Section 3 deserves examination. Some GPS stations were installed on hard bedrock or even the basement, but most of them lie on the top of sedimentary layers, especially in the two major basins considered. The problem of the decoupling between the surface and the depth is crucial in geodetic studies 


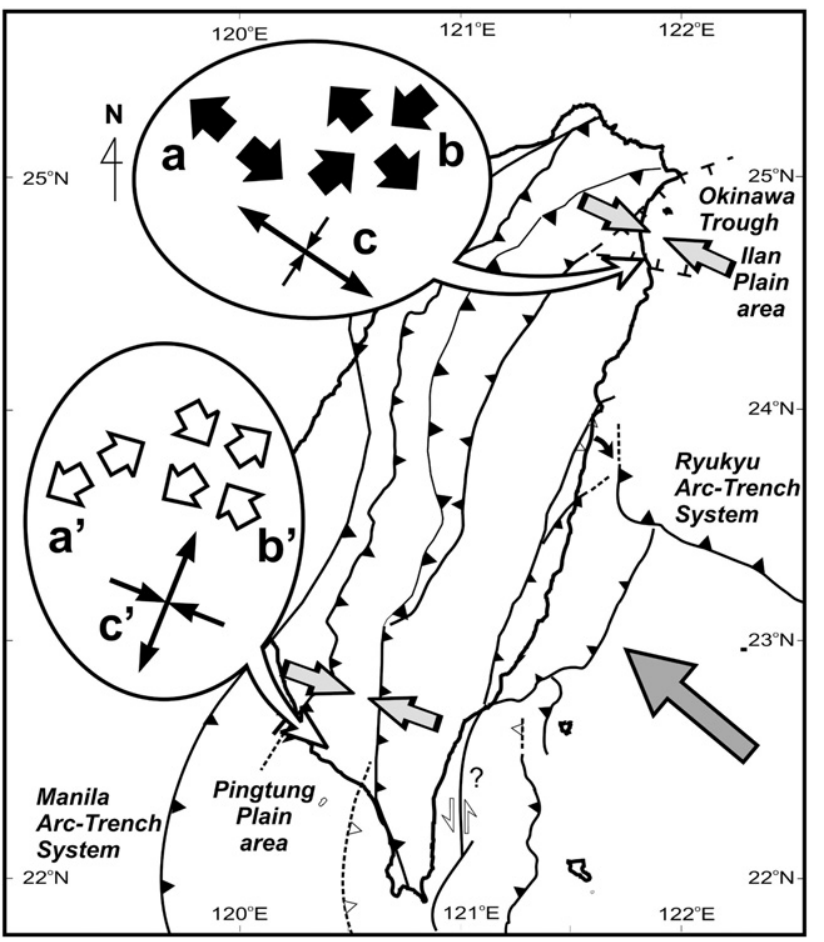

Fig. 13. Summary of results of determinations of three-dimensional stress (based on inversion of focal mechanisms, Section 5) and horizontal strain (based on inversion of geodetic displacement data, Section 4), for the Ilan Plain and Pingtung Plain areas. In each area: $(\mathrm{a}-\mathrm{a}$ ') extension related to normal faulting mechanisms, $\left(b-b^{\prime}\right)$ extension/compression related to strike-slip mechanisms, (c-c') extension/compression indicated by geodetic data. For strain results, most typical patterns have been selected near the coast (see Fig. 9 for details) and rotational components are not shown (see Fig. 8). See also Fig. 9 for deformation scales. For stress results, only the regimes interpreted as extrusion-related are inside bubbles (Figs. $10 \mathrm{a}$ and $\mathrm{b}$ and $12 \mathrm{~b}$ and $\mathrm{c}$ for details); corresponding pairs of arrows are black for well-constrained results ( $a$ and $b$ ), open for poorly constrained ones $\left(a^{\prime}\right.$ and $\left.b^{\prime}\right)$. The average trends of compression in the same areas (Figs. 11 and 12 a and d) are indicated by couples of grey arrows in the map. The extension related to the Okinawa Trough is not shown (Fig. $10 \mathrm{c}$ and d). Other symbols as in Fig. 1.

applied to tectonics. Blind thrusts or deep décollement surfaces may exist. By definition, GPS studies provide a picture of the deformation at the surface, which does not necessarily reflects the deformation at depth in a direct way. We consequently compared the results issued from independent analyses of displacement and strain (Sections 3 and 4) and seismotectonic stress (Section 5). The fact that similar results emerge from these independent approaches strongly suggests that they provide a reliable picture of the present-day tectonic regime. Otherwise, one should accept the idea that different biases in independent studies provide coincident results, which is against reasonable probability. This coincidence of results finally suggests that both the deviation of strain axes relative to stress axes and the difference between deformation at the surface and at depth can be regarded minor at the scale of the whole study.

Our strain in terms of horizontal strain are summarised by arrows $\mathrm{c}$ and $\mathrm{c}^{\prime}$ in Fig. 13. Considering our results about seismotectonic stress, two types of regimes, normal and strikeslip, reflect extrusion in northeast and southwest Taiwan
(Fig. 13, arrows $a, b, a^{\prime}$ and $b^{\prime}$ ). Although information about the vertical deformation is absent in our strain analysis, the results are consistent with those issued from three-dimensional analysis of seismotectonic stress. In each case (Ilan and Pingtung), a close mechanical link between these normal and strike-slip regimes, through permutation of maximum and intermediate principal stresses, is suggested by similar attitudes of minimum stress axes.

The consistency between independent analyses based on GPS data and focal mechanisms of earthquakes is illustrated by almost identical trends of compression and extension in the Ilan Plain area (Fig. 13, arrows a, b and c). In the Pingtung Plain area, a larger difference in trend emerges between the results obtained with these two approaches, despite general compatibility (Fig. 13, compare arrows $\mathrm{a}^{\prime}$ and $\mathrm{b}^{\prime}$ with arrows $\mathrm{c}^{\prime}$ ). This difference is a consequence of the very low number of earthquakes under the Pingtung Plain, resulting in determinations of stress regimes that may not accurately reflect the seismotectonic behaviour under this basin. Beneath the Pingtung Plain stricto sensu, earthquakes are very few so that our stress determinations are mainly constrained by earthquakes in surrounding areas, especially to the East and Northeast (Table 4 and Fig. 12).

In the Ilan Plain area of northeastern Taiwan, the present-day deformation is mainly characterised by elongation along an average trend $\mathrm{N} 120^{\circ} \mathrm{E}$ and perpendicular, $\mathrm{N} 30^{\circ} \mathrm{E}$ contraction (arrows c in Fig. 13). It has been shown that elongation is minor close to the mountain and rapidly increases towards the East and Southeast (Fig. 9b). In detail, pure elongation prevails towards the northeast (closer to the Okinawa Trough) whereas WSW-ENE elongation and NNE-SSW contraction dominate to the southeast (closer to the Ryukyu arc and trench), as Fig. 9a shows. The analysis of focal mechanisms of earthquakes thus reveals NW-SE trending extension in the Ilan Plain area, with both normal faulting and strike-slip faulting modes (arrows a and $b$, respectively, in Fig. 13). The direction of extension is $\mathrm{N} 135^{\circ} \mathrm{E}$ on average (Fig. $10 \mathrm{a}$ and b). The difference of $4^{\circ}$ between the trends of $\sigma_{3}$ of the normal and strike-slip type regimes is not significant (rows a and b in Table 2).

Whereas the geodetic analysis indicates strain patterns on land, earthquake mechanisms reveal seismotectonic stress in the onshore-offshore areas (compare Fig. 9b and Fig. 10). The trend difference of about $10-15^{\circ}$ between the axes of maximum strain rate $\left(\mathrm{N} 120^{\circ} \mathrm{E}\right.$ on average, arrow c in Fig. 13) and the minimum stress axes $\left(\mathrm{N} 131-135^{\circ} \mathrm{E}\right.$, arrows a and b in Fig. 13) thus concurs to highlight a progressive clockwise rotation of principal axes from the Ilan Plain towards its southwest offshore area, rather than revealing discrepancy between stress and strain. In addition to a multi-regime compression near the indenting northwest corner of the Philippine Sea Plate (not discussed herein), the active deformation of the Ilan area is clearly affected by two extensional regimes. One regime is generated by the neighbouring Okinawa extension (Fig. $10 \mathrm{c}$ and d), with $\mathrm{N}-\mathrm{S}$ extension and a minor $\mathrm{E}-\mathrm{W}$ extension resulting from stress permutation of $\sigma_{2} / \sigma_{3}$ type. The other regime is the expression of the lateral extrusion caused by the Taiwan orogeny (Fig. 10 a and b), with NW-SE extension 
involving strike-slip and normal type earthquakes associated through a $\sigma_{1} / \sigma_{2}$ stress permutation.

Near the southwestern tip of the collision zone, in the Pingtung Plain area, the present-day deformation is dominated by elongation along an average trend $\mathrm{N} 20^{\circ} \mathrm{E}$, with perpendicular contraction (arrows $\mathrm{c}^{\prime}$ in Fig. 13). Whereas pure ESE-WNW contraction prevails in the northern Pingtung Plain, close to the main collision zone, NNE-SSW elongation increases towards the sea to the southwest, closer to the Manila accretionary prism and trench (Fig. 7b). The analysis of focal mechanisms of earthquakes reveals NE-SW trending extension, with both normal faulting and strike-slip faulting modes (arrows $\mathrm{a}^{\prime}$ and $\mathrm{b}^{\prime}$, respectively, in Fig. 13). The direction of extension is $\mathrm{N} 60^{\circ} \mathrm{E}$ on average (Fig. $12 \mathrm{~b}$ and c). As for the Ilan Plain, a difference of $4^{\circ}$ exists between the trends of $\sigma_{3}$ of the normal and strike-slip type regimes, which should not be regarded as significant (rows b and c in Table 4).

As a major difference with northeastern Taiwan, few good quality focal mechanisms were available in the Pingtung Plain area, so that most earthquakes may reflect the behaviour of other seismotectonic units. This is especially the case for normal-type mechanisms, most of which occur in the southern Central Range and are not the expression of extrusion in the Pingtung Plain. The few remaining focal mechanisms in the Southern Pingtung Plain (Fig. 12c) cannot suffice to reliably characterise the seismotectonic stress in this area. A similar restriction is raised for the strike-slip type earthquakes related to NE-SW extension (Fig. 12b), the single mechanism located beneath the Pingtung Plain being one the rejected two mechanisms (row $b$ in Table 4).

In contrast with the Ilan Plain, the record of seismotectonic stress in the Pingtung Plain stricto sensu is very poor. This insufficient seismic information is not meaningless, it reflects a lesser mechanical strength of the crust. Most of the information about the mechanism of extrusion consequently results from the strain analysis, which indicates NNW-SSE elongation and WNW-ESE contraction (arrows $\mathrm{c}^{\prime}$ in Fig. 13).

These patterns of displacement (Fig. 8) and deformation and stress (Fig. 13) support an interpretation in terms of lateral extrusion and escape at both tips of the Taiwan mountain belt and collision zone (Fig. 14). Extrusion produces symmetrical senses of rotation in the Ilan and Pingtung areas (clockwise and anticlockwise respectively, see Fig. 8). It also results in nearly symmetrical transitions between compression that prevails close to the mountains and extension that increases towards the sea. Remarkably, this geometrical symmetry of the extrusion pattern is however altered by the different locations of the mechanically weak zones.

To the southwest (Pingtung Plain), the Manila arc-and-trench system trends more or less parallel to the NNE-SSW trending collision boundary, whereas to the northeast (Ilan Plain) the Ryukyu arc-and-trench system trends E-W, almost perpendicular to this boundary (Fig. 14). This major difference is a direct consequence of the plate boundary configuration in and around Taiwan (Suppe, 1984; Angelier, 1986). A N-S transition zone exists between the NNW-SSE Taiwan mountain belt and the $\mathrm{N}-\mathrm{S}$ Hengchun Ridge-Manila Trench system, which results from the southward propagation of the collision ( $\mathrm{Hu}$ et al., 1997). This transition zone also accounts for the large N-S dimension of the Pingtung Plain and the progressive N-S variation in strain rate patterns.

In contrast, a sharp boundary exists between the NNW-SSE Taiwan mountain belt and the $\mathrm{E}-\mathrm{W}$ trending system of the Ryukyu arc and trench and the Okinawa back-arc trough (Fig. 14). This boundary, which influences indentation ( $\mathrm{Lu}$ and Malavieille, 1994) and transition tectonics in northern Taiwan (Hu et al., 2002), is probably the reduced present-day expression of a major NW-SE trending left-lateral transform zone between the Luzon (to the SE) and Ryukyu (to the NW) subduction zones, the length of which progressively decreased as NW-SE plate convergence was continuing and finally reduced to zero before becoming right-lateral (Angelier, 1990a). Concerning the present-day structure and deformation, the presence of this sharp boundary explains the limited E-W extent of the Ilan Plain basin and the abrupt change in strain rate patterns from NW to SE.

Despite these differences inherited from the inherited structure and kinematics of the Taiwan region, the patterns of deformation of the Ilan Plain and Pingtung areas typically mimic particle flows moving toward mechanically weak domains. The weak domain is in both cases related to subduction. To the south, this weak domain is the Manila accretionary prism, and the maximum extrusion displacement and extension occur in its SSW direction relative to the Pingtung Plain area. This geometry accounts for the presence of NNE-SSW trending right-lateral strike-slip faults. To the north, the weak domain apparently coincides with the western tip of the back-arc Okinawa Trough, but the presence of the accretionary prism and subduction zone of the Ryukyu arc to the Southeast better accounts for the deformation pattern, with extrusion displacement and extension occurring towards the Southeast away from the Ilan Plain area. This kinematic pattern is consistent with pervasive left-lateral shear along a NW-SE direction. However, the opening of the Okinawa Trough certainly influences the extrusion pattern of the Ilan Plain area by increasing the mechanical weakness, which accounts for the surprisingly high displacement velocities and extension rates observed in this area with respect to southwestern Taiwan.

Whereas the shortening/compression trends in the Pingtung Plain are relatively consistent with the compression across the Taiwan belt, those of the Ilan Plain are nearly perpendicular to this compression, in agreement with two effects. First, the minor but significant left-lateral component of motion along the strike of the NNW-SSE trending Taiwan belt (e.g., Angelier et al., 2000) probably results in NWW-SSE shortening between the Backbone Range and the northern Hsuehshan Range. Second, the clockwise rotation of northern Taiwan is likely to induce belt-parallel contraction in the inner Hsuehshan Range and Ilan Plain, where the largest change in structural trend occurs.

The patterns of present-day displacement, deformation and stress are supported by geological information that suggests that variations related to the seismic cycle mainly affect amplitudes, rather than orientations (as is also suggested by the comparison between Fig. 5a and b, for GPS surveys before and after major 


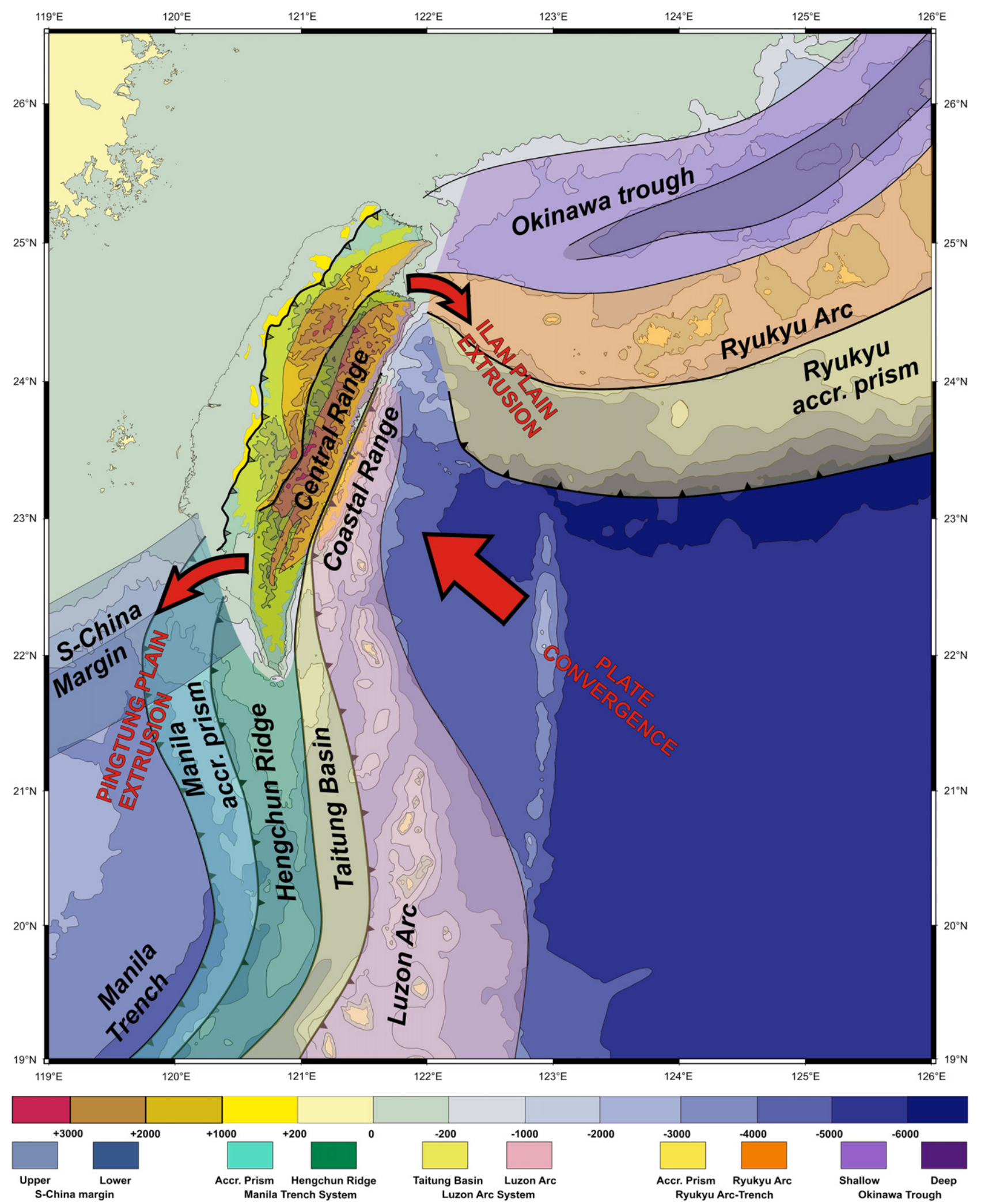

Fig. 14. Structure of the Taiwan collision zone, with lateral extrusion indicated. The elevations, from +4000 to $-7000 \mathrm{~m}$, are indicated by the colour scale. The additional transparent colours (in boxes below) indicate major units of the Taiwan region (see Fig. 1 for details). The straight red arrow indicates plate convergence. The curved red arrows indicate extrusion flow axes.

earthquakes). We infer that despite these variations the seismotectonic patterns presented in this paper deserve interpretation in terms of extrusion and escape at both tips of the
Taiwan collision zone (Fig. 14). To the south (Pingtung), the displacement is directed toward the Eurasian foreland (W) near the collision domain and toward the South China Sea (SW) near 
the subduction zone. To the north (Ilan), the displacement is directed toward the oceanic domain of the Philippine Sea (SE) near the subduction zone. In both cases, lateral extrusion and escape occur in a transition domain between the collision zone of Taiwan and an adjacent subduction zone.

\section{Acknowledgements}

This work has been supported by the France-Taiwan cooperation in Earth Sciences (French Institute in Taipei, French Centre National de la Recherche Scientifique and National Science Council of Taiwan), the Institut Universitaire de France and the ANR ACTS-Taiwan. This paper is product of the International Laboratory (LIA) ADEPT (Active Deformation and Environment Programme for Taiwan, http://jacques. angelier.googlepages.com/). We thank Dr Chi-Ching Liu, Michel Kasser and an anonymous reviewer, who did useful and constructive comments as referees. Dr C.-C. Liu gave us interesting information concerning the displacement of permanent GPS stations of the MOI network in the ITRF2000 global frame.

\section{References}

Angelier, J., 1984. Tectonic analysis of fault slip data sets. J. Geophys. Res. 89 (B7), 5835-5848.

Angelier, J., 1986. Preface. Geodynamics of the Eurasia-Philippine Sea plate boundary. Tectonophysics 125 , IX-X.

Angelier, J., 1990a. Foreword, Special Issue "Geodynamic Evolution of the Eastern Eurasian Margin”. Tectonophysics 183, VII-X.

Angelier, J., 1990b. Inversion of field data in fault tectonics to obtain the regional stress. III. A new rapid direct inversion method by analytical means. Geophys. J. Int. 103, 363-376.

Angelier, J., 2002. Inversion of earthquake focal mechanisms to obtain the seismotectonic stress IV - a new method free of choice among nodal planes. Geophys. J. Int. 150 (3), 588-609.

Angelier, J., Barrier, E., Chu, H.-T., 1986. Plate collision and paleostress trajectories in a fold-thrust belt: the Foothills of Taiwan. Tectonophysics 125 (1-3), $161-178$.

Angelier, J., Bergerat, F., Chu, H.-T., Lee, T.-Q., 1990. Tectonic-paleomagnetic analyses and the evolution of a curved collision belt: the Hsüeshan Range, northern Taiwan. Tectonophysics 183, 77-96.

Angelier, J., Chu, H.-T., Lee, J.-C., Hu, J.-C., 2000. Active faulting and earthquake risk: the Chihshang Fault case, Taiwan. J. Geodyn. 29, 151-185.

Barrier, E., Angelier, J., 1986. Active collision in eastern Taiwan: the Coastal Range. Tectonophysics 125 (1-3), 9-72.

Chai, B.-H.-T., 1972. Structure and tectonic evolution of Taiwan. Am. J. Sci. 272, 389-442.

Chan, Y.-C., Lu, C.-Y., Lee, J.-C., 2000. Orogen-parallel shearing in on-going mountain building: a case study form the southeastern Central Range of Taiwan. Eos. Trans. AGU, Fall Meet. Suppl., Abstract 81 (48).

Chang, C.-P., Angelier, J., Lee, T.-Q., Huang, C.-Y., 2002. From continental margin extension to collision orogen: structural development of the Hengchun Peninsula and tectonic rotation, southern Taiwan. Tectonophysics 361, 61-82.

Chang, C.-P., Chang, T.-Y., Angelier, J., Kao, H., Lee, J.-C., Yu, S.-B., 2003. Strain and stress field in Taiwan oblique convergent system: constraints from GPS observation and tectonic data. Earth Planet. Sci. Lett. 214, 115-127.

Chang, C.-P., Angelier, J., Lu, C.-Y., 2009. Polyphase deformation in a newly emerged accretionary prism: folding, faulting and rotation in the southern Taiwan mountain range. Tectonophysics 466, 395-408. doi:10.1016/j. tecto.2007.11.002.

Ho, C.-S., 1986. A synthesis of the geologic evolution of Taiwan. Tectonophysics $125,1-16$.
Ho, C.-S., 1975. An introduction to the geology of Taiwan: explanatory text of the geologic map of Taiwan. Ministry of Economic Affairs, R.O.C. 153 pp. Hou, C.-S., Hu, J.-C., Shen, L.-C., Wang, J.-S., Chen, C.-L., Lai, T.-C., Huang, C., Yang, Y.-R., Chen, R.-F., Chen, Y.-G., Angelier, J., 2005. Estimation of subsidence using GPS measurements, and related hazard: the Pingtung Plain, southwestern Taiwan. C.R. Geosci. 337, 1184-1193.

Hou, C.-S., Hu, J.-C., Chen, Y.-G., Chen, C.-L., Cheng, L.-W., Tang, C.-L., Huang, S.-H., Lo, C.-H., 2009. Plain acted as a westernmost extension of the Okinawa Trough. Tectonophysics 466, 344-355. doi:10.1016/j. tecto.2007.11.022.

Hsu, Y.-R. (1998). Study on surface deformation of Ilan plain, by means of GPS observation, Master Thesis of National Central University (in Chinese), Chungli, Taiwan, $108 \mathrm{pp}$.

Hu, J.-C., Angelier, J., 2004. Stress permutations: three-dimensional distinct element analysis accounts for a common phenomenon in brittle tectonics. J. Geophy. Res. 109, B09403. doi:10.1029/2003JB002616.

Hu, J.-C., Angelier, J., Lee, J.-C., Chu, H.-T., Byrne, D., 1996. Kinematics of convergence, deformation and stress distribution in the Taiwan collision area: 2D finite-element numerical modelling. Tectonophysics 255, 243-268.

Hu, J.-C., Angelier, J., Yu, S.-B., 1997. An interpretation of the active deformation of southern Taiwan based on numerical simulation and GPS studies. Tectonophysics 274, 145-169.

Hu, J.-C., Yu, S.-B., Angelier, J., Chu, H.-T., 2001. Active deformation of Taiwan from GPS measurements and numerical simulations. J. Geophys. Res. 106, 2265-2280.

Hu, J.-C., Yu, S.-B., Chu, H.-T., Angelier, J., 2002. Transition tectonics of northern Taiwan induced by convergence and trench retreat. In: Byrne, T.B., Liu, C.-S. (Eds.), Geology and Geophysics of an Arc-Continent Collision, Taiwan. Boulder, Colorado. Geol. Soc. Am. Special Paper, vol. 358 , pp. $147-160$.

Hu, J.-C., Chu, H.-T., Hou, C.-S., Lai, T.-H., Chen, R.-F., Nien, P.-F., 2006. The contributor to tectonic subsidence by groundwater abstraction in the Pingtung area, southwestern Taiwan as determined by GPS measurements. Quat. Int. 147, 62-69.

Hu, J.-C., Hou, C.-S., Shen, L.-C., Chan, Y.-C., Chen, R.-F., Huang, C., Rau, R.-J., Lin, C.-W., Huang, M.-H., Nien, P.-F., 2007. Fault activity and lateral extrusion inferred from velocity field revealed by GPS measurements in the Pingtung area of southwestern Taiwan. J. Asian Earth Sci. 31, 287-302 (doi:10.1016/j.jseaes.2006.07.0.20).

Kao, H., Jian, P.-R., 1999. Source parameters of regional earthquakes in Taiwan: July 1995-December 1996. Terr. Atmos. Ocean. Sci. 10, 585-604.

Kao, H., Angelier, J., 2001. Stress tensor inversion for the Chi-Chi earthquake sequence and its implications on regional collision. Bull. Seismol. Soc. Am. 91 (5), 1028-1040.

Kao, H., Jian, P.-R., 2001. Seismogenic patterns in the Taiwan region: Insights from source parameter inversion of BATS data. Tectonophysics 333, 179-198.

Kao, H., Jian, P.-R., Ma, K.-F., Huang, B.-S., Liu, C.-C., 1998. Moment-tensor inversion for offshore earthquakes east of Taiwan and their implications to regional collision. Geophys. Res. Lett. 25, 3619-3622.

Lacombe, O., Mouthereau, F., Deffontaines, B., Angelier, J., Chu, H.-T., Lee, C.-T., 1999. Geometry and Quaternary kinematics of fold-and-thrust units of southwestern Taiwan. Tectonics 18, 1198-1223.

Lacombe, O., Mouthereau, F., Angelier, J., Deffontaines, B., 2001. Structural, geodetic and seismological evidence for tectonic escape in SW Taiwan. Tectonophysics 333, 323-345.

Lee, J.-C., Angelier, J., 1994. Paleostress trajectory maps based on the results of local determinations: the 'LISSAGE' program. Comput. Geosci. 20 (2), 161-191.

Lee, J.-C., Angelier, J., Chu, H.-T., 1997. Polyphase history and kinematics of a complex major fault zone of the Taiwan mountain belt: the Lishan Fault. Tectonophysics $274,97-115$.

Lee, T.-Q., Angelier, J., Chu, H.-T., Bergerat, F., 1991. Rotations in the northeastern collision belt of Taiwan: preliminary results from paleomagnetism. Tectonophysics 199, 109-120.

Lee, T.-Q., Lee, J.-C., Chu, H.-T., Lu, C.-Y., Hu, J.-C., 1998 a. Paleomagnetic study in a folded zone of Hsuehshan Range, northeastern coast of Taiwan. Terrestrical, Atmosphereric and Oceanic Science (TAO), Taipei, vol. 9, No. 4, pp. 643-654. 
Lee, C.-T., Cheng, C.-T., Liaw, C.-W., Chang, Y.-B. (1998b). Active fault map of Taiwan, Inst. Applied Geology, Natl. Cent. Univ., Chungli, Taiwan.

Lee, J.-C., Chu, H.-T., Angelier, J., Hu, J.-C., Chen, H.-Y., Yu, S.-B., 2006. Quantitative analysis of surface coseismic faulting and postseismic creep accompanying the 2003, Mw $=6.5$, Chengkung earthquake in eastern Taiwan. J. Geophys. Res. 111, B02405. doi:10.1029/2005JB003612 21 pp.

Li, F.-C., Angelier, J., Chen, R.-F., Hsieh, H.-M., Deffontaines, B., Luo, C.-R., Wu, T.-T., Lin, M.-C., 2005. Estimates of present-day erosion based on sediment transport in rivers: a case study in Taiwan. C.R. Geosci. 337 (13), $1131-1139$.

Lin, A.T., Watts, A.B., 2002. Origin of the west Taiwan basin by orogenic loading and flexure of a rifted continental margin. J. Geophys. Res. 107, $2185-2203$

Liu, C.C., 1995. The Ilan Plain and the Southwestward Extending Okinawa Trough. J. Geol. Soc. China 38 (3), 183-193.

Liu, C.-S., Huang, I.-L., Tseng, L.-S., 1997. Structural features of southwestern Taiwan. Mar. Geol. 137, 305-319.

Liu, C., Liu, J.-P., Milliman, J.D., Lin, S., 2006. Tectonic-Climatic Controls on Lanyang River (Taiwan) Discharge to the Southwestern Okinawa Trough. Ocean Sciences AGU Meeting, 20-24 February 2006, Honolulu, Hawaii.

Lu, C.-Y., Malavieille, J., 1994. Oblique convergence, indentation and rotation tectonics in the Taiwan Mountain Belt: insights from experimental modeling. Earth Planet. Sci. Lett. 121, 477-494.

Lu, C.-Y., Angelier, J., Chu, H.-T., Lee, J.-C., 1995. Contraction, transcurrent, rotational and extensional tectonics: examples from northern Taiwan. Tectonophysics 246, 129-146.

Lu, C.-Y., Lee, T.-Q., Angelier, J., Lee, J.-C., Chu, H.-T., 2001. Anisotropic deformation and rotation tectonics during oblique convergence: examples from northeastern Taiwan. West. Pac. Earth Sci. 1 (3), 247-264.

Lundberg, N., Reed, D.L., Liu, C.-S., Lieske, J., 1997. Forearc-basin closure and arc accretion in submarine suture zone south of Taiwan. Tectonophysics 274 , $5-23$.

Malavieille, J., Lallemand, S.E., Dominquez, S., Deschamps, A., Lu, C.-Y., Liu, C.-S., Schnürle, P., 2002. Arc-continent collision in Taiwan: new marine observations and tectonic evolution. In: Byrne, T.B., Liu, C.-S. (Eds.), Geology and Geophysics of an Arc-Continent Collision, Taiwan. Boulder, Colorado. Geol. Soc. Am. Special Paper, vol. 358, pp. 187-211.
Molnar, P., Tapponnier, P., 1978. Active Tectonics of Tibet. J. Geophys. Res. 83, 5361-5375.

Mouthereau, F., Deffontaines, B., Lacombe, O., Angelier, J., 2002. Variation along the strike of the Taiwan thrust belt: basement control on structural style, wedge geometry, and kinematics. Geol. Soc. Am. Special Paper, vol. 358 , pp. 31-54.

Ratschbacher, L., Merle, O., 1991. Lateral extrusion in the Eastern Alps, part 2 structural analysis. Tectonics 2, 245-256.

Shen, L.-C., Hou, C.-S., Hu, J.-C., Chan, Y.-C., Huang, C., Lai, T.-C., Lin, C.-W., 2003. GPS measurements of active structure in Pingtung area, southwestern Taiwan. Spec. Publ. Cent. Geol. Surv. 14, 165-176.

Shyu, H., Sieh, K., Chen, Y.-G., Liu, C.-S., 2005. The neotectonic architecture of Taiwan and its implications for future large earthquakes. J. Geophys. Res. 110, B08402. doi:10.1029/2004JB003251.

Suppe, J., 1984. Kinematics of arc-continent collision, flipping of subduction and back-arc spreading near Taiwan. Mem. Geol. Soc. China 6, 21-33.

Tapponnier, P., Peltzer, A., Le Dain, Y., Armijo, R., Cobbold, P., 1983. Propagation extrusion tectonics in Asia: new insights from simple experiments with plasticine. Geology 10, 611-616.

Teng, L.S., 1990. Geotectonic evolution of late Cenozoic arc-continent collision in Taiwan. Tectonophysics 183, 57-76.

Tsai, Y.-B., 1986. Seismotectonics of Taiwan. Tectonophysics 125, 17-37.

Yeh, Y.-H., Barrier, E., Lin, C.-H., Angelier, J., 1991. Stress tensor analysis in the Taiwan area from focal mechanisms of earthquakes. Tectonophysics 200 , 267-280.

Yu, S.B., Chen, H.Y., 1994. Global positioning system measurements of crustal deformation in the Taiwan arc-continent collision zone. TAO 5, 477-498.

Yu, S.-B., Kuo, L.-C., 2001. Present-day crustal motion along the Longitudinal Valley Fault, eastern Taiwan. Tectonophysics 333, 199-217.

Yu, S.-B., Chen, H.-Y., Kuo, L.-C., 1997. Velocity field of GPS Stations in the Taiwan area. Tectonophysics 274, 41-59.

Yu, S.-B., Kuo, L.-C., Punongbayan, R.S., Ramos, E.G., 1999. GPS observation of crustal deformation in the Taiwan-Luzon region. Geophys. Res. Lett. 26, 923-926. 